\title{
Unobserved State Fragility and the Political Transfer Problem
}

\section{Citation}

Ahmed, Faisal Z., and Eric Werker. "Unobserved State Fragility and the Political Transfer Problem." Harvard Business School Working Paper, No. 13-009, July 2012.

\section{Permanent link}

http://nrs.harvard.edu/urn-3:HUL.InstRepos:9369298

\section{Terms of Use}

This article was downloaded from Harvard University's DASH repository, and is made available under the terms and conditions applicable to Open Access Policy Articles, as set forth at http:// nrs.harvard.edu/urn-3:HUL.InstRepos:dash.current.terms-of-use\#OAP

\section{Share Your Story}

The Harvard community has made this article openly available.

Please share how this access benefits you. Submit a story.

\section{Accessibility}


H A R VARD D U S I N E S S S C H O O L

\section{Unobserved State Fragility and the Political Transfer Problem}

Faisal Z. Ahmed

Eric Werker

\section{Working Paper}

13-009

July 26, 2012

Copyright (C) 2012 by Faisal Z. Ahmed and Eric Werker.

Working papers are in draft form. This working paper is distributed for purposes of comment and discussion only. It may not be reproduced without permission of the copyright holder. Copies of working papers are available from the author. 


\title{
Unobserved State Fragility and the Political Transfer Problem
}

\author{
By FAISAL Z. AHMED * AND ERIC WERKER ${ }^{\dagger}$
}

July 26,2012

Autocrats experiencing a windfall in unearned income may find it optimal to donate to other countries some of the windfall in order to make the state a less attractive prize to potential insurgents. We put forward a model that makes that prediction, as well as the additional predictions that the recipients of the aid may themselves become more repressive with high levels of aid and experience conflict with medium levels of aid. We call these joint phenomena the political transfer problem, and argue that the largest windfall of the $20^{\text {th }}$ century, the period from 1973-85 during which oil prices were at all-time highs, produced long-run political dynamics consistent with the model. In particular, major oil exporters have been politically repressive, generous with foreign aid when oil prices are high, and free of civil war; in contrast, the recipients of petro aid were relatively repressive (and peaceful) during the period of high oil prices, but subject to civil war when oil prices fell and aid was reduced. Surprisingly, the political transfer problem did not seem to materialize when oil prices again began to creep up in the $21^{\text {st }}$ century; this nonexistence of the problem can be explained by the model against the backdrop of evolving geopolitics and economics.

JEL codes: F35, F59, N45, O19, Q34

\footnotetext{
* Oxford University, faisal.ahmed@ nuffield.ox.ac.uk.

${ }^{\dagger}$ Harvard Business School, ewerker@hbs.edu .Corresponding author.

The authors are grateful to Shawn Cole and Lou Wells as well as participants at the Harvard development faculty brownbag seminar for comments and suggestions, and we thank Daniel Schwab and Kaitlyn Tuthill for excellent research assistance. An earlier version of this paper "Can Foreign Aid Buy Stability?" benefited greatly from comments and suggestions from Alberto Alesina, Charles Cohen, Martin Feldstein, and Roger Owen, as well as seminar audiences at Harvard Business School, the International Political Economy Society, and the NBER. Ahmed thanks Nuffield College and the Niehaus Foundation at Princeton University for financial support and Werker thanks the Division of Research and Faculty Development at Harvard Business School. The usual disclaimer applies.
} 


\section{Introduction}

Fragile and failed states are of increasing concern to policymakers confronting a bifurcating world. Many foreign aid agencies are now concentrating their efforts in a smaller number of countries, most of which are fragile states (e.g. Sumner 2011, Kiros 2007). From a security perspective, these countries are seen as sources of conflict, terrorism, refugees, and epidemics (Patrick 2007). From a developmental perspective, they are where the "bottom billion" live, confronted by poverty, resource dependence and corruption, bad governance, and unfavorable geography (Collier, 2007).

But the popular view of fragile states as those suffering from violence and abject poverty misses the distinction between the condition of fragility and its most observable symptoms. The OECD defines fragile states as "those failing to provide basic services to poor people because they are unwilling or unable to do so" (OECD 2006) and the British and Canadian aid agencies had similar definitions focused on the provision of social services (Stewart and Brown 2010). Yet Libya, it may be argued, was fragile long before its dramatic and violent insurgency in 2011 even though it had an effective transfer system. The same would be true of any number of countries where the threat of violence is present, if below the surface, and the specter of widespread poverty is one global downturn away from being realized. Perhaps for this reason, some newer definitions of state fragility focus on the risk as well as the realization of state failure (e.g. Stewart and Brown 2010). But risk, of course, is harder to observe and moreover does not imply any immediate danger for the rest of the world.

In this paper we seek to describe how the dynamics of unobserved state fragility may generate negative consequences for other countries. The mechanism, specifically, is that resource rents may accrue that allow an autocrat to ward off poverty and violence at home, even as the threat of conflict remains. What we call the "political transfer problem" is as follows. When a financial windfall is sufficiently large that its presence could lead to the fragile peace breaking down (via increased rent seeking), the autocrat may find it optimal to shed some of the excess windfall in the form of foreign aid to poorer countries. By reducing the "prize" for a would-be insurgent, the autocrat can maintain stability in his country. However, once that transfer reaches another, poorer, country, it introduces the very resource-curse political dynamics from unearned income that the donor autocrat had been carefully managing — except this time, the recipient 
country may not have sufficient rents to ward off a threat from the opposition, which can lead to civil conflict. Both the autocrat facing the windfall as well as the autocrat well funded by foreign aid may be rich enough to use repression as a means of keeping the peace, but in so doing they repress the most conspicuous symptom of state fragility without treating its cause.

Aid can indeed generate resource-curse dynamics when it arrives in the wrong country. Consider Siad Barre's Somalia. From 1969 through 1990 Somalia received, on average, foreign aid equal to $18.5 \%$ of its GDP — from the Soviet Union, then the United States, plus the Arab League and the United Nations, among others (Besteman, 1996, 581). Following a failed irredentist drive into Ethiopia and the loss of Soviet support, Barre dropped a scientific socialist platform and adopted clanism as a method for maintaining power. This transition occurred under a climate of increasing foreign aid. Barre favored the clans in his inner circle and bombed his rival clan's strongholds. This policy would ultimately lead to his destruction in the form of "civil wars of revenge" as the excluded clans expressed their dissatisfaction with Barre's policy of divide-and-rule. "Foreign aid," observed one Somalia scholar, "provided the glue that held the system together in spite of internal waste and corruption" (Adam, 1999, 175).

Somalia, of course, slipped into complete state failure following the withdrawal of outside support in the early 1990s. Over two decades later, it is characterized by nearly all the afflictions of fragile states, from conflict and refugees to poverty and bad governance. But what does "unobserved fragility" look like? In the model we propose, it looks like state fragility except without the symptoms - it looks like a risk of conflict in which a change in unearned income can suddenly cause the country to erupt in violence.

In Section II we build upon a series of theoretical formulations of political violence in a fragile state (Besley and Persson 2009, 2010, 2011a). In the model, the population is divided into two groups, one of which is the incumbent and the other the opposition. The incumbent gets access to the sovereign rents - the unearned income from natural resources or foreign aid — and distributes them to the two groups, but favoring its own. Both groups can invest in violence: the incumbent financing an army out of the public purse, and the opposition financing an insurgency from its own wages. A higher investment in violence, ceteris paribus, will lead to a higher likelihood of being in power the next period. Our model stages the timing to allow the incumbent to give aid before the opposition has made its investment in violence. The model generates the key results of the political transfer problem. One, the incumbent may find it optimal to give aid 
so as to reduce the unearned income and hence the "prize" for the opposition to take power-and in so doing, maintaining peace. Two, when another country receives that aid, the increase in unearned income may lead to higher likelihood of civil conflict and repression. In Section III, we attempt to demonstrate that the political transfer problem may have occurred at least once in recent history, on a massive scale. The 1973 oil embargo produced a dozen years of sky-high oil prices, filling the coffers of the producer states. At the same time, autocracies such as Saudi Arabia initiated generous foreign aid programs while simultaneously increasing the level of repression - measured by a reduction in the constraints on the executive and in political rights. These countries were able to prevent internal conflict in spite of the fresh flow of petrodollars. The aid that was given by the Gulf oil producers largely favored Muslim countries, which were also relatively autocratic. It appears as though the oil producers exported the resource curse through their foreign aid programs. Compared with non-Muslim non-oil producers, the recipients of the petro aid windfall experienced higher repression during the oil price shock, and-once the aid began to fall, following the collapse in oil prices in the mid-1980s - a substantial increase in civil war. That the aid was correlated with the price of oil allows a quasi-natural-experimental approach to test the hypothesis that the aid windfall led to higher conflict in the recipient countries.

We develop the model to argue for the possible existence of a political transfer problem, using a parsimonious framework that applies to both aid donor and recipient. Our empirical results paint what we believe is a picture consistent with the model. To be sure, the different motivations for aid donation as well as the possible pernicious effects of aid receipt are myriad (Werker 2012) and neither the model nor the empirics in this paper can definitively test among them. But aid certainly can confer domestic legitimacy in ways that other forms of shedding unearned income cannot.

The political transfer problem is a reference to the original "transfer problem," which described the relative price distortions inherent in Germany's reparation payments after the Great War. Writing in the Economic Journal, Keynes described the transfer problem as not the German authorities' ability to collect sufficient taxes to be used as reparations, but "converting the German money so received into foreign currency" (1929, 1). If making substantial reparations meant that German demand had to fall, but foreign demand were for different products than what would have been produced for German consumers, then a shift in production would need to 
occur in order for the value of those taxes not to be diminished away in relative price movements. The transfer problem enjoyed a vigorous debate in the interwar years (most famously between Keynes and Bertil Ohlin) and fell out of fashion, with only the occasional attempt at resurrection (e.g. Brakman and van Marrewijk 1998).

We chose the term "political transfer problem" since it also involves an effect on two macroeconomic equilibria resulting from a transfer of resources from one country to another. In the economic transfer problem, the flow of resources may lead to the production of goods and services being unbalanced. In the political transfer problem, the flow of resources may lead to the incentives for investment in political violence to become unbalanced. For the sending country, that unbalancing is in the "right" direction: by sending aid abroad, the prize for wouldbe insurgents becomes reduced, and the country is able to sustain peace and a lower probability of transferring power. For the recipient country, however, the unbalancing increases the rewards of capturing the state, and in so doing may lead to conflict or greater repression.

Characterizing the political transfer problem also squares off a two-by-two matrix that has been heretofore incomplete. Unearned income can theoretically generate both economic and political problems domestically. When a state experiences a surge in income from natural resources (Cordon and Neary 1982) or foreign aid (Rajan and Subramanian 2011), the increased demand for the currency can bring about appreciation of the real exchange rate, or Dutch disease, making other potential exports less attractive. From a political perspective, the increase in unearned income can lead to the so-called resource curse, which describes the political conflict and corruption that may result from the struggle to control the rents (e.g. Collier 2007). The traditional transfer problem results when "unearned" income must be transferred to another country and the price mechanism gets tested (possibly necessitating a reallocation of production), just as with Dutch disease. Similarly, the political transfer problem explains how politics are distorted when unearned income is transferred from one country to another; it is the internationalization of the resource curse. Figure 1 depicts the two-by-two matrix:

\section{Figure 1: The Perils of Domestic and Foreign Unearned Income}

\begin{tabular}{l|ll} 
& Economic challenge & Political challenge \\
\hline Domestic unearned income & Dutch disease & Resource curse \\
Foreign unearned income & The transfer problem & Political transfer problem
\end{tabular}


That the literature on the transfer problem has been largely silent over the past seventy years provides some possible hint as to why the political transfer problem has remained unarticulated. Since the World Wars, there has been no situation of war reparations involving a similar share of global GDP. After World War I, for example, Germany was required to repay around \$64 billion over 30 years, although by the time Keynes was writing in 1929 the Young Plan had reduced the debt to $\$ 26.3$ billion, approximately 6 percent of global GDP, paid out over 59 years. ${ }^{3}$ Although Germany never completed its reparations payments (thanks in no small part to the hyperinflation of the inter-war years), the sheer size of the payments, and the potential distortions to the economics, did not go unnoticed.

For its part, the political transfer problem may also have occurred only once on such a grand scale. The transfer of resources between autocrats in the Gulf maintaining a political equilibrium of repression and peace at home, and poor autocrats around the world who would go on to experience more repression and then civil conflict, totaled $\$ 43$ billion over the period 197385 , equivalent to nearly 1 percent of global GDP in $1973,{ }^{4}$ very similar in magnitude to the reparations payments agreed in Keynes' time. As unprecedented as the oil price crisis of that period was, it was not unique. In 2003, oil prices again began to rise - this time fueled by the growth of developing countries whose steady rise in GDP was starting to hit a level significant enough to get noticed. Oil prices would again reach the levels they hit (in real terms) in 1979, and culminate in the commodity crisis of 2008 which only went away with the financial crisis of the same year. But prices remained high and the coffers of the oil exporters were again flush for a sustained period.

This time, however, there would be no outsized transfer to the poor Muslim world. The relationship between oil prices and the aid differential to Muslim versus non-Muslim non-oil producers, which had held for the previous four decades, fell apart in 2003. We searched for a parsimonious explanation for this phenomenon but could find none. Instead, we argue in Section IV that the non-appearance of the political transfer problem in the post-2003 oil price rise is due to the combined effects of at least three factors. One, the Gulf oil producers had seen their own

\footnotetext{
${ }^{3}$ Young Plan figure from encyclopedia.com; global GDP estimated at \$3.5 trillion from Maddison figures \$2.7 trillion in 1913 and \$4.5 trillion in 1940 (1990 dollars; Maddison 2010) and converted to 1929 dollars using BLS urban CPI.

${ }^{4}$ Aid is sum of non-DAC bilateral aid and Arab multilateral from the OECD; global GDP from the World Development Indicators.
} 
populations swell with some of the highest growth rates in the world, but their oil revenues were not growing at the same rate. As a result, the post-2003 windfall was smaller on a per capita basis, and as a result the formerly generous aid donors may have needed to keep the resources at home to manage the more demanding populations. Two, in the past decade and a half, the number and size of sovereign wealth funds around the world exploded. This may have given autocrat rentiers an alternative technology to deal with oil windfalls and keep them for the future while still keeping them untouchable to would-be insurgents. Three, while oil prices returned to their previous highs, the world had in the meantime gotten richer, and other donors more generous, relegating the petro aid to a less impressive quantity. In addition, the traditional donors began favoring countries with more open regimes, thus favoring non-Muslim recipients. The net result was to take away any aid windfall for the countries that had enjoyed it in the late 1970s and early 1980s.

Section V concludes. Given these significant changes, it is likely that the political transfer problem may never again arise on such a large scale. That said, the presence of its last incarnation is still being felt. Several decades on, the recipients of Gulf largesse remained more repressive and less democratic than those countries that were passed over in the distribution of the oil windfalls. It has only been the strength and contagion of the Arab Spring that has begun to undo the sticky politics of managing group conflict through transfers and spending on the domestic security apparatus.

This paper is related to several strands of political economy literature. One, it is situated in the emerging economics research on fragile states. For example, Besley and Persson (2011b) have attempted to sharpen the discussion from numerous policy papers (e.g. Zoellick 2009) on fragile states to articulate how fragile states end up the way they do. Two, the paper is related to the literature on the resource curse and unearned rents (e.g., Sachs and Warner, 1995; Robinson et al, 2006; Caselli and Tesei, 2011). Three, by discussing how an autocratic rentier manages domestic politics, it speaks to the extensive literature on distributive or rentier states (e.g. Mahdavy 1970; Auty 2001). Finally, by investigating the link between aid windfalls and conflict, it contributes to our knowledge of the political consequences of aid (Svensson, 2000; Collier and Hoeffler, 2002; Nunn and Qian, 2010; Besley and Persson 2011a). 


\section{The Political Transfer Problem}

In this section we aim to show the potential existence of a political transfer problem. To do so, we take the now-canonical model of a fragile state developed by Besley and Persson (e.g. 2009, 2010, 2011a) and allow the incumbent to burn off excess unearned income in the form of foreign aid. With a few steps, we are able to show that a rich, peaceful, but ultimately fragile country can export its latent conflict to the recipients of its largesse. In the next section we will argue that such a phenomenon is not only theoretically possible, but may have occurred when the oil crisis of 1973 led to unimaginable wealth flowing into the coffers of the politically underdeveloped oil exporters on the Persian Gulf.

\section{The Basic Set-up}

Our model closely follows Besley and Persson 2011a. There are two groups of equal size in a population normalized to 1 with wage $w$. Time is infinite, though since there are no state variables we model a single generation which is equivalent to any other. One group, the incumbent (denoted $I n c$ ) is in power, while the other group (Opp) is in the opposition. Being in power allows the incumbent to favor its own when distributing state resources $R$ which can be thought of as a rentier's unearned income from natural resources and aid. The incumbent is restricted in how much it can favor its own population: when it gives a transfer of 1 to its own population, it must give $\sigma \in[0,1]$ to the other group. This results in per capita transfers of $r^{\text {Inc }}$ and $r^{O p p}$. Utility for both groups are described in $V^{I n c}$ and $V^{O p p}$.

Both the incumbent and the opposition have access to a violence technology: the incumbent can raise an army from the state's resources, while the opposition can mount an insurgency financed by its own members' income. An army of size $A \epsilon[0,1]$ costs $w A$ to raise. For simplicity, we assume that there is one size army available to the opposition, and there are two sizes of armies available for the incumbent (low and high), so $A^{O p p} \in\left\{0, A_{L}{ }^{O p p}\right\}$ and $A^{I n c} \in\{0$, $\left.A_{L}^{I n c}, A_{H}^{I n c}\right\}$. Power changes hands stochastically with probability $\gamma$, but either side can improve their chances by investing in violence so $\mathrm{\gamma}\left(A^{O p p}, A^{I n c}\right) \in(0,1)$, which ensures that no one is assured of winning or losing. The primary modification to Besley and Persson's model is that the incumbent may choose to give foreign aid $D \geq 0$ to reduce the temptation of the opposition to 
mount an insurgency. The value of the prize for the group in power, normalized by dividing by the wage, is equal to $Z=(R-D) / w$.

The timing at any generation is as follows:

1. Group $I$ starts in power.

2. $\quad R$ and $w$ are realized.

3. Group $I$ has the option to dispose of $D \geq 0$ through giving aid.

4. Group $O$ chooses violence level 0 or $A_{L}{ }^{o p p}$.

5. Group I observes this, chooses violence level $0, A_{L}^{I n c}$, or $A_{H}{ }^{I n c}$.

6. A new incumbent, $I^{\prime}$, is chosen according to the conflict function.

7. Group $I^{\prime}$ chooses the level of transfers.

8. Payoffs are realized and the current generation dies.

We make several other simplifying assumptions. More violence always improves a group's probability of taking or holding power, or $\mathrm{\gamma}\left(O, A^{I n c}\right)<\mathrm{\gamma}\left(A_{L}^{O p p}, A^{I n c}\right)$, and $\mathrm{\gamma}\left(A^{O p p}, 0\right)>\mathrm{\gamma}\left(A^{O p p}\right.$, $\left.A_{L}^{I n c}\right)>\mathrm{\gamma}\left(A^{O p p}, A_{H}^{I n c}\right)$ for all $A^{O p p}, A^{I n c}$. Opposition violence is never undefended, so if $A^{O p p}=$ $A_{L}{ }^{O p p}$, then $A^{I n c}>0$. Opposition and incumbent break ties by choosing the lower level of violence and aid.

\section{Investing in Violence and Aid}

The government has total resources $R$, which it spends on transfers to the two groups $r^{I n c^{\prime}}$ and $r^{O p p '}$ (whose identities are determined by the violence function), aid $D$, and the incumbent's army $A^{I n c}$, so its budget constraint is:

$$
R-r^{I n c^{\prime}} / 2-r^{O p p^{\prime}} / 2-D-w A^{I n c} \geq 0
$$

The incumbent is restricted in the degree to which it can favor its own group, giving $\sigma \in[0,1]$ to the other group for every 1 transferred to its own, so assuming that the government budget constraint holds with equality, we have:

$$
r^{I n c^{\prime}}=2(1-\Theta)\left[R-D-w A^{I n c}\right]
$$


where, for convenience, $\Theta=\sigma /(1+\sigma) \epsilon[0,1 / 2]$.

To keep the model as simple as possible, utility is equal to consumption, which is wages plus transfers. The expected payoff to the incumbent is then:

$$
V^{I n c}\left(w, R ; D, A^{O p p}, A^{I n c}\right)=w+\left[(1-\Theta)-\mathrm{\gamma}\left(A^{O p p}, A^{I n c}\right)(1-2 \Theta)\right] 2\left[R-D-w A^{I n c}\right]
$$

The term $\left[(1-\Theta)-\mathrm{y}\left(A^{O p p}, A^{I n c}\right)(1-2 \Theta)\right]$ represents the share of the end-of-period transfers that the incumbent expects to get. If the incumbent retains power, they receive a share of $(1-\Theta)$ of transfers while if they lose power they receive a share of $\Theta$, meaning the amount they lose is $(1-$ $2 \Theta)$, and that occurs with probability $\mathrm{y}\left(A^{O p p}, A^{I n c}\right)$. The opposition's expected payoff is similar, with the primary difference that they have to fund their own violence from their wages:

$$
V^{O p p}\left(w, R ; D, A^{O p p}, A^{I n c}\right)=w\left(1-A^{O p p}\right)+\left[\Theta+\gamma\left(A^{O p p}, A^{I n c}\right)(1-2 \Theta)\right] 2\left[R-D-w A^{I n c}\right]
$$

This allows us to define the groups' optimal actions. Working backwards from the end of a period, the incumbent chooses the violence level:

$$
\hat{A}^{I n c}=\operatorname{argmax} V^{I n c}\left(w, R ; D, A^{O p p}, A^{I n c}\right) \text { for } A^{I n c} \in\left\{0, A_{L}^{I n c}, A_{H}^{I n c}\right\}
$$

Because of the timing, $D$ and $A^{O p p}$ have been chosen earlier and are known to the incumbent, and we assume that if $A^{O p p} \neq 0$ then $\hat{A}^{I n c} \neq 0$. We define $\hat{A}^{I n c}(0)$ and $\hat{A}^{I n c}\left(A_{L}^{I n c}\right)$ as the levels of violence that the incumbent will choose in response to levels of violence 0 and $A_{L}^{I n c}$ from the opposition. The opposition, having observed the choice of aid, chooses its optimal level of violence:

$$
\hat{A}^{O p p}=\operatorname{argmax} V^{O p p}\left(w, R ; D, A^{O p p}, \hat{A}^{I n c}\left(A^{O p p}\right)\right) \text { for } A^{O p p} \in\left\{0, A_{L}^{I n c}\right\}
$$

Finally, in the first step, the incumbent will choose the optimal level of aid:

$$
\widehat{D}=\operatorname{argmax} V^{I n c}\left(w, R ; D, \hat{A}^{O p p}(D), \hat{A}^{I n c}\left(\hat{A}^{O p p}(D)\right)\right) \text { for } D \geq 0
$$

where $\hat{A}^{O p p}(D)$ is the optimal level of incumbent violence for aid level $D$. 


\section{Characterizing Optimal Investment in Violence}

Recall that $Z=(R-D) / w$ is a measure of the prize for having power, given the amount of aid that has been disposed of, normalized for convenience by $w$. We define $Z^{I n c}\left(A^{O p p} ; A_{l}^{I n c}\right.$, $A_{2}{ }^{I n c}$ ) as the threshold level of $Z$ in which the incumbent is indifferent between investing between any two levels of violence $A_{1}^{I n c}$ and $A_{2}{ }^{I n c}$ given that the opposition is investing $A^{O p p}$. First we solve for the incumbent's optimal investment in violence as the prize gets larger.

Proposition 1: There exist thresholds for $Z$ that determine $\hat{A}^{I n c}(0)$ and $\hat{A}^{I n c}\left(A_{L}^{O p p}\right)$, the optimal incumbent violence against peace and violence, respectively. The thresholds satisfy either (i):

1) $\hat{A}^{I n c}(0)=0$ if $Z \leq Z^{I n c}\left(0 ; 0, A_{L}^{I n c}\right)$, so $Z^{I n c}\left(0 ; 0, A_{L}^{I n c}\right)$ is the threshold where the incumbent is indifferent between using 0 violence and $A_{L}{ }^{\text {Inc }}$, given that the opposition is using 0 .

2) $\hat{A}^{\text {Inc }}(0)=A_{L}^{\text {Inc }}$ if $Z^{\text {Inc }}\left(0 ; 0,{A_{L}}^{\text {Inc }}\right)<Z \leq Z^{I n c}\left(0 ; 0, A_{H}^{\text {Inc }}\right)$

3) $\hat{A}^{I n c}(0)=A_{H}^{\text {Inc }}$ if $Z>Z^{\text {Inc }}\left(0 ; 0, A_{H}^{I n c}\right)$

or (ii):

1) $\hat{A}^{\text {Inc }}(0)=0$ if $Z \leq Z^{I n c}\left(0 ; 0, A_{H}^{I n c}\right)$

2) $\hat{A}^{I n c}(0) \neq A_{L}^{I n c}$ for all $Z$

3) $\hat{A}^{\text {Inc }}(0)=A_{H}^{\text {Inc }}$ if $Z>Z^{I n c}\left(0 ; 0, A_{H}^{I n c}\right)$

In addition, (iii) is always satisfied:

4) $\hat{A}^{I n c}\left(A_{L}^{O p p}\right)=A_{L}^{I n c}$ if $Z \leq Z^{I n c}\left(A_{L}^{O p p} ; A_{L}^{I n c}, A_{H}^{I n c}\right)$

5) $\hat{A}^{I n c}\left(A_{L}^{O p p}\right)=A_{H}^{I n c}$ if $Z>Z^{I n c}\left(A_{L}^{O p p} ; A_{L}^{I n c}, A_{H}^{I n c}\right)$

Case (i) means that as $Z$ goes from zero to infinity, the incumbent's optimal response to peace will be peace, then low violence, then high violence. Case (ii) means that the incumbent never wants to use low violence against peace; it's always better to use peace or high violence. Either case is possible depending on the parameters. The thresholds in (iii) mean that as $Z$ goes from 
zero to infinity, the incumbent's optimal response to violence will be low violence, then high violence.

Proof: See appendix A.

Next we solve for the opposition's optimal investment in violence as the prize $Z$ gets larger.

Proposition 2: For all $Z \neq Z^{I n c}\left(A_{L}^{O p p} ; A_{L}^{I n c}, A_{H}^{I n c}\right), \hat{A}^{O p p}$ is non-decreasing in $Z$. For sufficiently low $Z$, both groups are peaceful, and for sufficiently high $Z$, they both use the maximum available violence.

This proposition describes the optimal level of incumbent violence as the prize grows. For very low values of $Z$, the reward for success is so small that fighting is worthless. For very high values of $Z$, the reward is so large that the incumbent is guaranteed to use high violence regardless of the opposition's choice, and the opposition will fight.

There is only one threshold for $Z$ where the opposition can switch from violence to peace, the $Z$ where the incumbent is indifferent between using high and low violence against an insurgency. Crossing that level means that opposition violence will be met with the incumbent's maximum response, so a higher prize may deter the opposition. In all other cases, increasing the prize cannot induce peace.

Proof: See appendix A.

\section{Characterizing Aid Outflows}

We wish to show that some fragile states_-or, more specifically, states at risk of failure that may appear stable - may find it optimal to give aid to other countries. We define $D^{\text {min }} \geq 0$ as the lowest $D$ such that $\hat{A}^{O p p}(D)=0$, meaning that $D^{\text {min }}$ is the lowest amount of aid that will cause the opposition to be peaceful. In order to do this, we need to verify that $D^{\min }$ is well-defined. For example, if the opposition would be peaceful for any value $D \in(x, y)$ then there is no minimum, while $[x, y]$ or $[x, y)$ does have a well-defined minimum.

Lemma 1: $D^{\text {min }}$ is well-defined.

Proof: See appendix A. 
Now we wish to show why these countries give aid within the incentive structure of the model. Essentially, it is to reduce the prize sufficiently that the opposition no longer finds it optimal to mount an insurgency. Proposition 3 establishes that when an incumbent gives aid, there is no insurgency at home. Lemma 2 demonstrates that the optimal aid strategy is either giving nothing or just enough to deter violence. Proposition 4 shows that when the opposition would otherwise use violence, it may be optimal to give aid. The mechanism behind these propositions is simply that when the incumbent faces a potential insurgency, it gives just enough aid to make the investment in violence not pay off. Combined with Proposition 1, these propositions imply that being a fragile aid donor may often coincide with domestic repression, defined by high investment in violence by the incumbent combined with a peaceful opposition.

Proposition 3: Optimal aid $\widehat{D}>0$ implies optimal opposition violence $\hat{A}^{O p p}=0$.

Proof: See appendix A.

Lemma 2: $\widehat{D}_{\in}\left\{0, D^{\text {min }}\right\}$, where $D^{\text {min }} \geq 0$ is the lowest $D$ such that $\hat{A}^{O p p}(D)=0$, meaning that $D^{\text {min }}$ is the lowest amount of aid that will cause the opposition to be peaceful.

Proof: See appendix A.

Proposition 4: Suppose the opposition uses violence in the absence of aid. For sufficiently small $D^{\text {min }}$, optimal aid $\widehat{D}>0$.

Proof: See appendix A.

This generational model should be taken as illustrative for how unearned income is distributed versus burned off. In reality, sending aid abroad in one particular year may not significantly reduce the value of capturing the state, since being in control of the state gives a party greater control over future resource extraction. While the model can be read as describing a more medium-term process of using aid to weaken the value of the state to a potential insurgent, in Appendix B we develop such a model explicitly. The model in Appendix B extends the current model to allow the incumbent to invest in capital as well as distributing the state resources or giving them away in the form of foreign aid. We find a solution in which the 
incumbent underinvests in capital, reducing the present discounted value of the state, so as to diminish the expected gains to the opposition of an insurgency.

\section{The Consequences of Aid Inflows}

We have just discussed how a fragile rentier may wish to give aid when it experiences a high amount of unearned income, so that the likelihood of conflict at home is reduced. In this subsection, we articulate what may happen when this aid arrives in another fragile state. Besley and Persson (2011a) model a potential hierarchy of violence from peace via repression to civil war as unearned income rises, and find broad support for their prediction in cross-country data using quasi-experimental methods. By allowing our incumbent to burn off excess unearned income by giving aid, and restricting them to a stepwise violence investment function, we ended up with a theoretical possibility of higher unearned income resulting in repression. Turning to the recipient countries, we wish to investigate whether in fact the aid they receive can also support more two-sided violence as well as repression. We find that it is possible to observe low levels of aid leading to low-investment civil war and higher levels of aid leading to repression. These are not necessarily the most likely outcomes, but there are nonetheless reasonable conditions within the model in which such an ordering might occur. The higher unearned income leading to a greater degree of repression is consistent with the results in Caselli and Tesei (2011).

Proposition 5: In order to observe peace for $Z_{L}$, civil conflict for $Z_{M}$ and repression for $Z_{H}$, with $Z_{L}<Z_{M}<Z_{H}$, the following conditions are necessary and sufficient:

1) $Z_{L} \leq\left(\left(A_{L}^{O p p} / 2\right)+\left[\Theta+\gamma\left(A_{L}^{O p p}, \hat{A}^{I n c}\left(A_{L}^{O p p}\right)\right)(1-2 \Theta)\right] \hat{A}^{I n c}\left(A_{L}^{O p p}\right)-\left[\Theta+\gamma\left(0, \hat{A}^{I n c}(0)\right)(1-\right.\right.$ $\left.2 \Theta)] \hat{A}^{I n c}(0)\right) /\left((1-2 \Theta)\left(\mathrm{\gamma}\left(A_{L}^{O p p}, \hat{A}^{I n c}\left(A_{L}^{O p p}\right)\right)-\mathrm{\gamma}\left(0, \hat{A}^{I n c}(0)\right)\right)\right) \equiv Z^{T}\left(Z_{L}\right)$

2) $Z_{L} \leq \min \left\{Z^{I n c}\left(0 ; 0, A_{L}^{I n c}\right), Z^{I n c}\left(0 ; 0, A_{H}^{I n c}\right)\right\}$

3) $Z_{M}>\left(\left(A_{L}^{O p p} / 2\right)+\left[\Theta+\mathrm{\gamma}\left(A_{L}^{O p p}, \hat{A}^{I n c}\left(A_{L}^{O p p}\right)\right)(1-2 \Theta)\right] \hat{A}^{I n c}\left(A_{L}^{O p p}\right)-\left[\Theta+\mathrm{\gamma}\left(0, \hat{A}^{I n c}(0)\right)(1-\right.\right.$ $\left.2 \Theta)] \hat{A}^{I n c}(0)\right) /\left((1-2 \Theta)\left(\mathrm{\gamma}\left(A_{L}^{O p p}, \hat{A}^{I n c}\left(A_{L}^{O p p}\right)\right)-\mathrm{\gamma}\left(0, \hat{A}^{I n c}(0)\right)\right)\right) \equiv Z^{T}\left(Z_{M}\right)$

4) $Z_{H} \leq\left(\left(A_{L}^{o p p} / 2\right)+\left[\Theta+\gamma\left(A_{L}^{O p p}, \hat{A}^{I n c}\left(A_{L}^{O p p}\right)\right)(1-2 \Theta)\right] \hat{A}^{I n c}\left(A_{L}^{O p p}\right)-\left[\Theta+\mathrm{\gamma}\left(0, \hat{A}^{I n c}(0)\right)(1-\right.\right.$ 2Ө)] $\left.\hat{A}^{I n c}(0)\right) /\left((1-2 \Theta)\left(\mathrm{\gamma}\left(A_{L}^{O p p}, \hat{A}^{I n c}\left(A_{L}^{O p p}\right)\right)-\mathrm{\gamma}\left(0, \hat{A}^{I n c}(0)\right)\right)\right) \equiv Z^{T}\left(Z_{H}\right)$

5) $Z_{H}>\min \left\{Z^{I n c}\left(0 ; 0, A_{L}^{\text {Inc }}\right), Z^{\text {Inc }}\left(0 ; 0, A_{H}^{\text {Inc }}\right)\right\}$ 
The first condition means that the opposition will be peaceful when the prize is small $\left(Z_{L}\right)$, and the second means that the incumbent will be peaceful in response. This will always happen for a sufficiently low value of $Z$. The third and fourth conditions mean that the opposition will attack when observing an intermediate prize of $Z_{M}$, but remain peaceful against a larger prize of $Z_{H}$. The interpretation is that a wealthy incumbent $\left(Z_{H}\right)$ can crush an attacker with high violence, so the opposition would have little chance of winning the state through violence and would prefer to receive transfers instead. Because we assume that no insurgency is undefended, the third condition is equivalent to civil conflict (violence from both sides). The fifth condition says that a wealthy incumbent uses violence against a peaceful opposition, the definition of repression.

In Besley and Persson's (2011a) model, there is a hierarchy of violence from peace to civil conflict via repression. While such a result could obtain from different parameter values in this model than those which satisfy the conditions above, we note that if we include a $Z_{V H} \gg Z_{H}$ that civil conflict would then result, so a possible hierarchy with this model would be peace to civil conflict to repression to civil conflict again. We refrain from including a $Z_{V H}$ in this proposition because this model also allows the aid recipient to burn off excess aid in the form of aid to yet a third country, thereby preventing the final stage of civil conflict from emerging. Such cases of autocratic aid recipients acting as aid donors are relatively rare and are not the focus of this paper.

Proof: See appendix A. Appendix A also describes some values over which these conditions are maintained. We note the right-hand side of conditions (2) and (3) are algebraically the same, but evaluated at the different $Z$ s, so have different values.

We now turn to the empirics and attempt to show that the conditions described in this model have occurred at least once in modern history. An autocratic rentier found it optimal to manage the threat of conflict at home from a windfall in unearned income through a generous foreign aid program; that aid led to repression and peace in the recipient countries when the aid was at its most generous, but when the transfers fell back to lesser levels civil conflict broke out. 


\section{Evidence}

In this section we seek to show that the political transfer problem may have existed, on a grand scale, when the Gulf oil producers saw the price of their main export rise more than fivefold in just a matter of years. We will show that the price of oil was correlated with a surge in foreign aid from the oil producers, and we will argue that this may have helped stabilize their domestic politics. We will show that the aid favored non-oil producing Muslim countries, and argue that it led to slower democratic reforms in the recipient countries and more internal conflict - particularly when the aid started to go away. Since the wars of liberation in Africa were occurring over a similar time period, we use a natural experimental approach on the conflict, utilizing a difference-in-difference between the Muslim and non-Muslim non-oil producers.

\section{Taming the Windfall}

In this subsection we aim to give evidence that Propositions 3 and 4 describe the oil price boom for the Gulf rentiers: aid can be a way for an autocrat to reduce violence at home, and when an autocrat is giving aid there is no civil war at home.

Since 1973, when the price of oil began to skyrocket, the Gulf nations of the Organization of the Petroleum Exporting Countries (OPEC) have been extremely generous in their distribution of aid. Estimates by Neumayer $(2003,134)$ suggest these countries doled out 1.5 percent of their GDP between 1974 and 1994, which amounted to 13.5 percent of all aid given out over this period. They also favored Muslim countries in the disbursement of this aid. No doubt some motivation was political: the Gulf countries were trying to quell unrest due to the huge inequality among their co-religionists (between the oil haves and have-notes), as well as to "assure them[selves] a clear position of dominance within the Muslim world" (Kepel, 2002, 6970).

Domestically, the decision to export some of their oil windfalls in the form of foreign aid may have proved politically effective for Gulf oil exporters (Table 1). During the period of high oil prices, these countries remained non-democratic and experienced extremely low levels of political violence, despite the surge in state resources (the $R$ in the model) that would be tempting for the opposition to grab. In 1973, the typical Gulf exporter was non-democratic with a 
government that enjoyed near "unlimited" political authority. ${ }^{5}$ Throughout the oil boom (19731985), these standard indicators of authoritarian stability averaged the highest for any recorded period, and began to fall a little with the price of oil, but were still comparatively strong. As Table 1 shows, since the oil boom the typical Gulf aid donor has remained authoritarian with a very negative POLITY score (i.e. thus failing below the conventional threshold to qualify as a democracy), where the executive (government) has exercised "unlimited" to "slightly moderated unlimited" political authority. Moreover, the incidence of high (two-sided) violence entailing at least 1,000 battle deaths stayed remarkably low, particularly when oil prices were high — and contrary to what could be expected with a generic model of a higher prize for the state leading to more civil conflict.

\section{Table 1: Political Stability in Gulf Oil Producers}

\begin{tabular}{lcccc} 
& POLITY & $\begin{array}{c}\text { POLITY } \\
\text { Oil price }(2009 \$)\end{array}$ & $\begin{array}{c}\text { Incidence of civil war } \\
\text { Composite Score }\end{array}$ & $\begin{array}{c}\text { Executive Constraints } \\
>1000 \text { battle deaths per year }\end{array}$ \\
\hline Before: 1960-1972 & 11.98 & -6.26 & 1.94 & 0.05 \\
& $(0.98)$ & $(5.88)$ & $(1.86)$ & $(0.22)$ \\
During: 1973-1985 & 60.87 & -7.23 & 1.70 & 0.03 \\
& $(21.40)$ & $(4.37)$ & $(1.38)$ & $(0.17)$ \\
After: 1986-1999 & 27.26 & -6.33 & 2.07 & 0.05 \\
& $(5.29)$ & $(4.20)$ & $(1.24)$ & $(0.21)$ \\
Post 2000: $2000-2008$ & 53.47 & -5.54 & 2.36 & 0.01 \\
& $(21.64)$ & $(4.39)$ & $(1.22)$ & $(.12)$ \\
\hline
\end{tabular}

Notes: Summary statistics for Gulf (Muslim) oil producers. Standard deviations reported in parentheses. POLITY composite score ranges on a -10 to +10 scale, where larger values imply a higher quality of democratic governance. The POLITY executive constraints index is measured on a 7 point index, where lower values mean a less constrained executive.

\section{Where did the Aid Go?}

In contrast to the oil producers, the non-oil producing Muslim countries have experienced more tumult since $1972 .{ }^{6}$ We argue that this tumult can be explained by the OPEC aid received

\footnotetext{
${ }^{5}$ POLITY score ranges from -10 to +10 , where larger values correspond to a higher quality of democratic governance. Following the convention, countries with POLITY scores in the -10 to 0 range are deemed nondemocratic (autocratic). With respond to political authority, the average value on the "executive constraints" index (from POLITY IV) was 1.75, which corresponds to a government with "unlimited" to "moderately limited" constraints. The executive constraints index ranges on a 1 to 7 where higher values correspond to a more constrained (accountable) leader/government. The corresponding values are: 1 (unlimited authority), 2 (intermediate category), 3 (slight to moderate limitation on executive authority), 4 (intermediate category), 5 (substantial limitations on the executive authority), 6 (intermediate category), 7 (executive parity or subordination).

${ }^{6}$ A country is defined as Muslim if at least 70 percent of its population identify with the Islamic faith. Following convention, we classify a country as poor on the World Bank's criteria. Our estimating sample is restricted to poor
} 
by these poor countries. During the oil price boom, the aid these countries received looked like unearned income flowing to the state. Unlike current foreign aid from the World Bank, for example, donors in the Gulf gave their money with comparatively few strings attached. Most aid was in the form of block grants to finance ministries. According to Hunter (1984): "the largest part of OPEC aid has still consisted of general balance of payment and budgetary support." Hallwood and Sinclair concur: "Most OPEC aid is given on very favourable terms and conditions from the recipient's point of view. A large proportion of this aid is given on a grant basis, otherwise loan terms are with low interest rates and long grace and amortisation periods" (1981, 100-101). And while aid from Western donors has often been tied towards contracts with the donor country, "Arab aid has practically never been tied, with the exception of relatively unimportant specific loans and grants for oil purchases" (Neumayer, 2002, 15).

Two facts about the pattern of Gulf states' aid form the basis for a natural experiment in this paper that we are both seeking to explain with the theoretical model, as well as to take advantage of to test the hypotheses suggested by Proposition 5. One, this aid favors other Arab and non-Arab Muslim recipients (Neumayer, 2003). Two, the aid is highly correlated with the price of oil. The programs only began in earnest following the oil crisis of 1973 (Hallwood and Sinclair 1981; Hunter 1984), and the aid fluctuations closely follow oil prices. ${ }^{7}$ These two key facts form the basis of a natural experiment, in which Muslim countries were the unique recipients of an aid windfall that only lasted as long as the price of oil remained high.

Figure 2 plots average aid receipts across non-oil producing Muslim and non-Muslim countries since 1960. From 1960 to around 1973, average aid receipts in Muslim and nonMuslim countries were remarkably similar. This changed at the onset of the first oil shock. Between 1973 and until the mid-1980s (during the oil price boom), Muslim countries received substantially higher amounts of aid (percent of GDP) compared to non-Muslim countries. Over this period, on average, Muslim countries received 6.2 percentage points of GDP more aid than non-Muslim countries. Aid receipts in Muslim countries tapered off thereafter and for the most

(as defined by the World Bank), non-oil producing (as classified by British Petroleum 2009) countries. We identify Muslim countries as those where at least 70 percent of the population identify with the Islamic faith. All other countries are non-Muslim. Table D1 identifies the sample of Muslim and non-Muslim poor, non-oil exporting countries.

${ }^{7}$ The best measure of OPEC aid (not required for later analysis which uses total aid) is imperfect; it relies on data from the Source OECD data set, summing non-OECD aid with Arab multilateral aid. 
part since the early 1990s remained largely similar to inflows received in non-Muslim countries. As is apparent from the figure, Muslim countries experienced a windfall in foreign aid over the period that roughly corresponds to the high oil price years.

Figure 2: Foreign Aid Receipts by Muslim and non-Muslim Countries, Non-Oil Producers

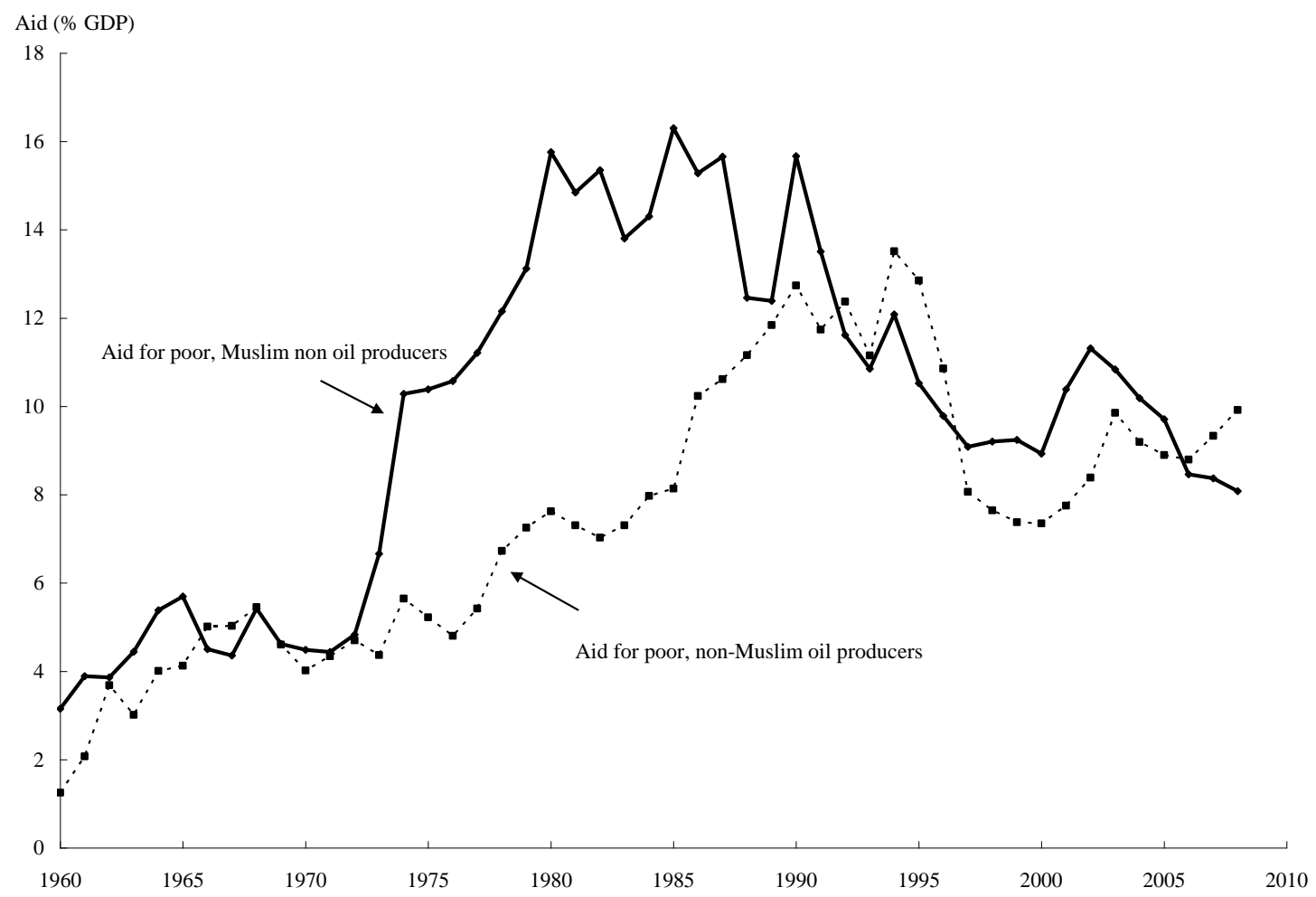

To show a clearer sense of this correlation, Figure 3 depicts movements in the price of oil (right axis) and superimposes the difference in foreign aid as a percentage of GDP between nonoil producing Muslim and non-Muslim countries (left axis). As is evident from the figure, the amount of bonus aid doled out to Muslim countries from Gulf donors tracks the price of oil. Moreover, difference-in-difference estimates from the high oil price period (1973-1985) and the surrounding low oil price periods (1960-1972, 1986-1999) between Muslim and non-Muslim countries reveal that these aid differentials are statistically significant. ${ }^{8}$

\footnotetext{
${ }^{8}$ These results are presented in appendix table $\mathrm{C} 1$. The aid windfall that Muslim countries got during the period 1973-1985 relative to the prior period (1960-1972) equals 5.8 percent of GDP. This difference is highly statistically significant ( $\mathrm{p}$-value<0.05). Moving to the period 1986-1999, the statistics indicate that 5.3 percentage points of that windfall went away. Again, this difference-in-difference is highly statistically significant. For the post-2000 period when the oil price began to rise again, Muslim countries did not seem to experience a statistically significant bonus in foreign aid as the correlation between high oil prices and aid receipts in Muslim countries weakened (we explore why in section IV).
} 
Figure 3: Oil price and the Aid Windfall to Muslim Countries, Non-Oil Producers

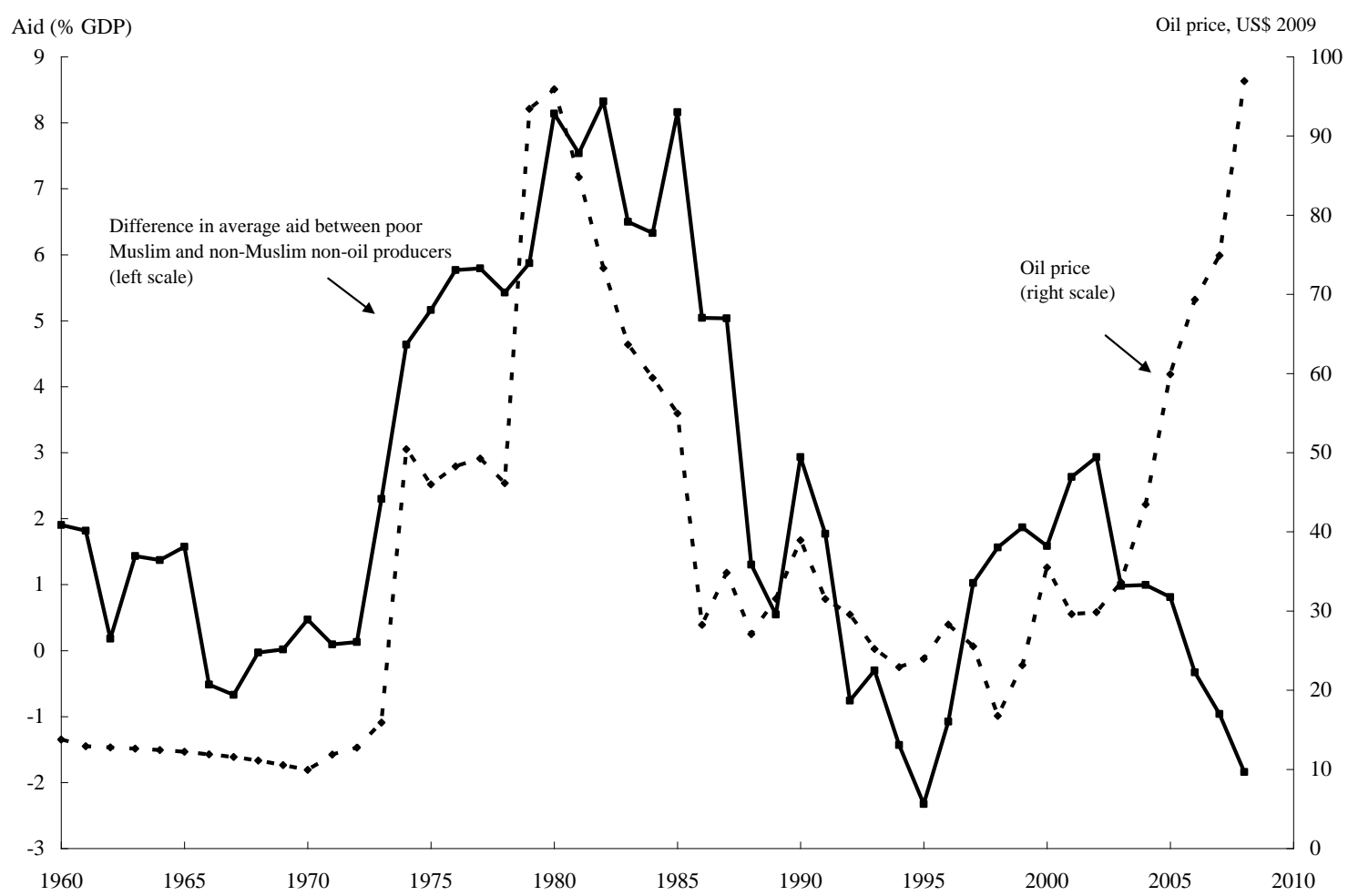

Figures 2 and 3 underlie our empirical strategy to identify the effect of aid on political stability. Such an identification strategy is attractive since the world price of oil is plausibly exogenous from the differential between Muslim and non-Muslim countries' internal economic and political conditions in poor, non-oil producing aid recipients. In the lead-up to the first oil price shock, Muslim and non-Muslim countries did not differ significantly on observable economic (GDP per capita) and political (POLITY, executive constraints, and incidence of civil war) conditions. ${ }^{9}$ This means that the typical Muslim non-oil producing aid recipient (our “treated" sample) was similar to non-Muslim oil producing aid recipients (our "control" sample) prior to the reception of the oil-price induced aid shock ("treatment"). Given this similarity in political-economic conditions prior to the oil shocks, it is plausible that systematic pre-treatment differences in these conditions are unlikely to have affected subsequent political dynamics across Muslim and non-Muslim countries (except via aid).

\footnotetext{
${ }^{9}$ Appendix table D2 compares the average quality of politics, political stability (incidence of civil war), and average income conditions in Muslim and non-Muslim countries in year prior to the oil shock (1972). The difference in means across these observable characteristics is not statistically significant, although Muslim countries were slightly poorer, less democratic, and more peaceful.
} 
This natural experimental setting has been employed elsewhere to study the effects of aid on economic growth and political survival. Werker et al (2009) find that this aid windfall had no substantive effect on medium-term economic growth in non-oil producing Muslim countries, but did increase government consumption, in particular on imported goods. Ahmed (2012) employs this natural experiment to show that foreign aid (coupled with remittance inflows) can extend the tenure of leaders in non-democracies. Neither paper examines whether the aid affects political repression, nor the temporal impact of aid on subsequent political violence in these countries. Thus, we harness this natural experimental setting to test the theoretical predictions from section II.

Consistent with the predictions in Section II, as shown above, oil producers limit the domestic windfall, exporting some of their export receipts abroad — in the form of largely untied foreign aid to non-oil producing Muslim countries. Moreover, these Gulf donors remained nondemocratic and did not experience political conflict during this period. However, as we document below and in line with the predictions from Proposition 5, these aid windfalls fostered political repression, leading to a subsequently higher propensity of two-sided political violence (high-intensity civil war) when this aid windfall disappeared.

\section{Transferring Repression}

Proposition 5 posits that higher unearned government income can foster conflict at low levels of aid and repression at higher levels. Since the nature of the aid transfer to poor Muslim countries was initially larger, and subsequently smaller, corresponding to a high and medium $Z$ in the recipient countries, we first document the effects on repression. We consider two dimensions of political repression: political authority held by the government (using the executive constraints index from POLITY IV created by Marshall et al 2010) and the political rights enjoyed by the population (using political rights index from Freedom House 2010). We rescale the 7-point executive constraint index such that higher values imply a government that is more repressive, or in the language of the indicator, less constrained. ${ }^{10}$ The executive constraint

\footnotetext{
${ }^{10}$ The original series in POLITY lies on a 1 to 7 point scale, where smaller values correspond to a less constrained executive. For instance, a score of 1 indicates an executive with "unlimited authority." A score of 3 characterizes a leader with "slight to moderate limitation on executive authority." A score of 2 is the "intermediate" category. A score of 7 denotes "executive parity or subordination", meaning the leader is accountable (subordinate) to another group (e.g., legislature, voters). We re-scale the POLITY executive constraints such that higher values capture executives with greater authority. Thus, with our measure, a score of 7 implies "unlimited authority", 6
} 
index has been used to measure a country's quality of property rights (Acemoglu and Johnson 2005) and is perhaps the most significant political variable separating democracies from autocracies (Gledistch and Ward 1997). ${ }^{11}$ The measure of political rights is a 7 point index where higher values correspond to more repression, or fewer political freedoms. For example, Freedom House classifies countries with an index value of 1 and 2 as "free" and those with scores of 5, 6, and 7 as "not free." In practice for each index, lower values correspond to a higher degree of democratic governance with appropriate checks on the executive's political authority and greater political freedom.

Figure 4 depicts the overall trends of political repression in Muslim aid recipients and oil prices. These countries became more repressive during the period of high oil prices and then gradually became less repressive. Throughout the 1970s and early 1980s, governments in Muslim countries tended to enjoy "slight to moderate limitation on executive authority" and citizens were "not free." 12 Since the 1990s political conditions became less repressive, albeit slowly, as both series exhibited a downward path. These trends are consistent with the predictions from the formal model: the highest levels of repression during the low-conflict and high aid period (1973-1985), but the persistence of repression even as conflict became more twosided (1985-2000).

(intermediate), 5 (slight to moderate limitation on executive authority), and so forth. With our measure, 1 characterizes "executive parity or subordination."

${ }^{11}$ Gleditsch and Ward (1997) claim that "although the degree of executive constraints accounts for only 4 of the possible 10 democracy scale points, all our analyses point strongly to the conclusion that this variable virtually determines the democracy and autocracy scale values" (380).

${ }^{12}$ From 1970-1985, Muslim countries averaged 4.8 and 5.6 on our measure of executive constraints and political rights, respectively. Based on the POLITY and Freedom House respective classifications, this corresponds to "slightly moderated" executive authority and "not free" political rights. 


\section{Figure 4: Repression in Non-Oil Producing Muslim Aid Recipients}

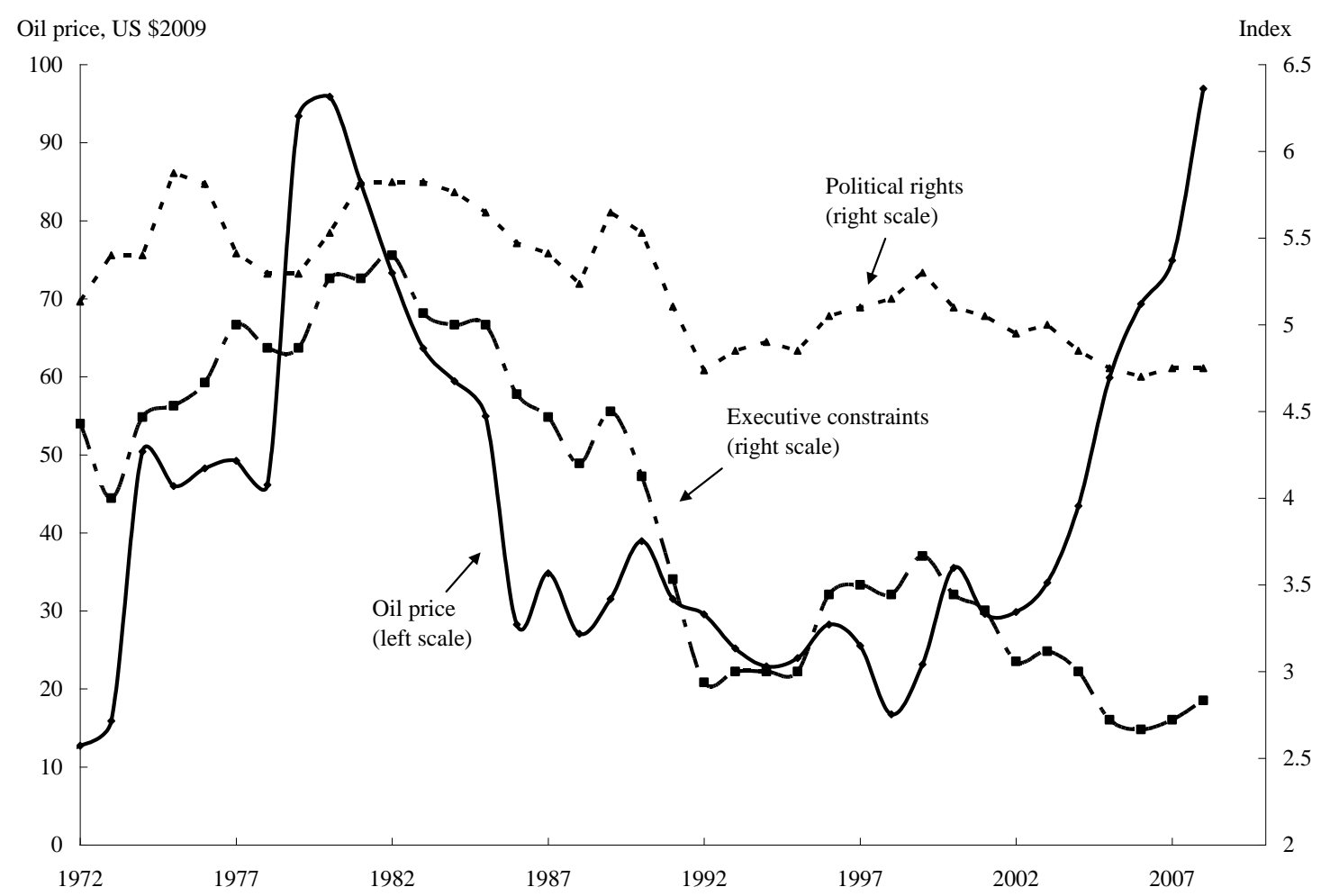

To quantify these trends, Table 2 shows non-Muslim countries have become increasingly less repressive (on average) than Muslim countries since the 1970s. For example, during the oil boom period, the typical Muslim country was nearly 0.5 index points higher than the typical nonMuslim country on the political rights dimension. These differences between Muslim and nonMuslim countries have become more pronounced over time (and are statistically significant). Indeed, in the contemporary period, Muslim countries tend to be 1 and 1.4 index points more repressive than non-Muslim countries on the measures of executive constraints and political rights respectively. 
Table 2: Political Repression across Muslim and Non-Muslim Non-Oil Producers, by Periods of Low and High Oil Prices

\section{Panel A}

Dependent variable:

Executive Constraints

\begin{tabular}{lcccccc} 
& Non-Muslim & Muslim & Difference & Std Error & Difference-in-difference & Std Error \\
\hline Before: 1960-1972 & 4.02 & 4.13 & 0.11 & {$[0.454]$} & & \\
During: 1973-1985 & 4.22 & 4.88 & 0.66 & {$[0.401]^{\wedge}$} & 0.55 & {$[0.353]^{\wedge}$} \\
After: 1986-1999 & 2.79 & 3.65 & 0.86 & {$[0.388]^{* *}$} & 0.21 & {$[0.352]$} \\
Post 2000: 2000-2008 & 1.89 & 2.97 & 1.08 & {$[0.428]^{* *}$} & 0.22 & {$[0.387]$}
\end{tabular}

\section{Panel B}

Dependent variable:

\begin{tabular}{lcccccc} 
Dependent variable: & \multicolumn{6}{c}{ Political rights } \\
& Non-Muslim & Muslim & Difference & Std Error & Difference-in-difference & Std Error \\
\hline Before: 1960-1972 & 4.92 & 5.13 & 0.21 & {$[0.183]$} & & \\
During: 1973-1985 & 5.17 & 5.61 & 0.44 & {$[0.381]$} & 0.22 & {$[0.404]$} \\
After: 1986-1999 & 4.11 & 5.15 & 1.05 & {$[0.343]^{* * *}$} & 0.61 & {$[0.362]^{*}$} \\
Post 2000: $2000-2008$ & 3.47 & 4.89 & 1.41 & {$[0.390]^{* * *}$} & 0.37 & {$[0.277]$}
\end{tabular}

Notes: Standard errors are clustered by country reported in brackets.

$\wedge=$ significant at $15 \% ; *=$ significant at $10 \% ; * *=$ significant at $5 \%: * * *=$ significant at $1 \%$.

The difference-in-differences estimates, while not universally significant at conventional thresholds, are positive. On balance, Table 2 demonstrates that non-Muslim countries experienced a significant decline in repression, while it was more muted in Muslim countries.

\section{Transferring Conflict}

We now turn to the potential effect of the aid windfall on internal conflict in the recipient countries. To measure political violence, we use armed conflict data (ACD) from UCDP/PRIO spanning the period 1960-2008 (Gleditsch et al 2002; updated by Harbom et al 2008). ACD has been widely used in empirical studies of civil war (e.g., Collier et al 2003; Miguel et al 2004; Besley and Persson 2010). We capture two thresholds of political violence: civil wars involving at least 25 battle deaths per year and high intensity civil war involving at least 1,000 battle deaths per year and restrict each to non-internationalized internal war so as to capture the type of group conflict in the model. The latter, higher threshold level of violence is consistent with two-sided conflicts involving a government and well-armed rebel groups and has been used accordingly in related studies (e.g., Besley and Persson 2011a). The measures of civil war are binary variables equal to one if the relevant battle death threshold has been met, and zero otherwise.

Figure 5 depicts the overall trends in oil prices and the incidence of civil war in poor, non-oil producing Muslim countries. At both thresholds of civil war, conflict remained relatively 
stable and low until the early 1980s during a period of high oil prices (and therefore higher aid inflows). The propensity for conflict in these countries picked up dramatically in from 1982 through the late 1990s, when oil prices declined (and with them, aid inflows).

\section{Figure 5: Incidence of Civil War in Non-Oil Producing Muslim Aid Recipients}

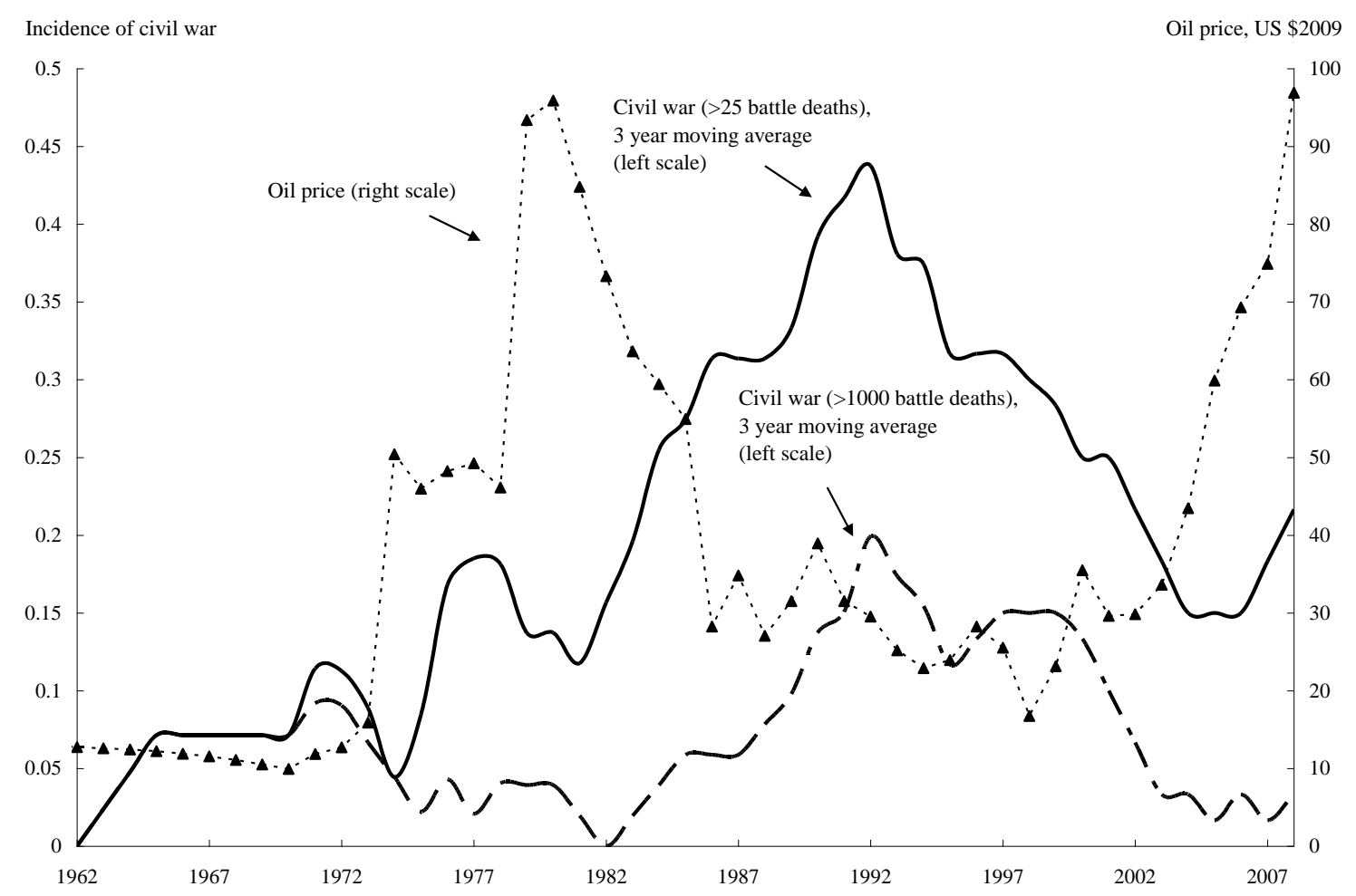

Since these recipients do not produce any oil, the positive correlation between oil prices and political stability (i.e., lower incidence of civil war) is unlikely to operate directly via oil prices, which might on their own go in the opposite direction as high commodity prices can lead to discontent and riots - as the 2008 food crisis showed so vividly. Rather, as we show below, it likely operates through the oil-price-induced foreign aid disbursed by Gulf oil producers to poor, non-oil-producing Muslim countries. Thus, this natural experiment offers a rare opportunity in history to draw plausible causal inferences of foreign aid on political stability.

Figures 6 and 7 examine the relationship between the aid differential and the conflict differential at the low and high thresholds of violence across Muslim and non-Muslim countries in the sample. Consistent with the reduced form relationship illustrated in figure 3 , in periods in which Muslim countries received more aid than non-Muslim countries (1973-1985), the conflict differential was low, and in most years negative (especially for high intensity war involving two- 
sided violence). That is, Muslim countries experienced less conflict than non-Muslim countries when they received comparatively more aid (and when the amount of repression was especially high, as the previous subsection showed). This pattern reversed from the mid-1980s until the early 2000s. As the aid differential plummeted due to falling oil prices (and as the level of repression began to fall), Muslim countries were substantially more likely to experience civil war.

Figure 6: The Muslim/Non-Muslim Foreign Aid and Conflict Differentials, Non-Oil Producers (at least 25 battle deaths per year)

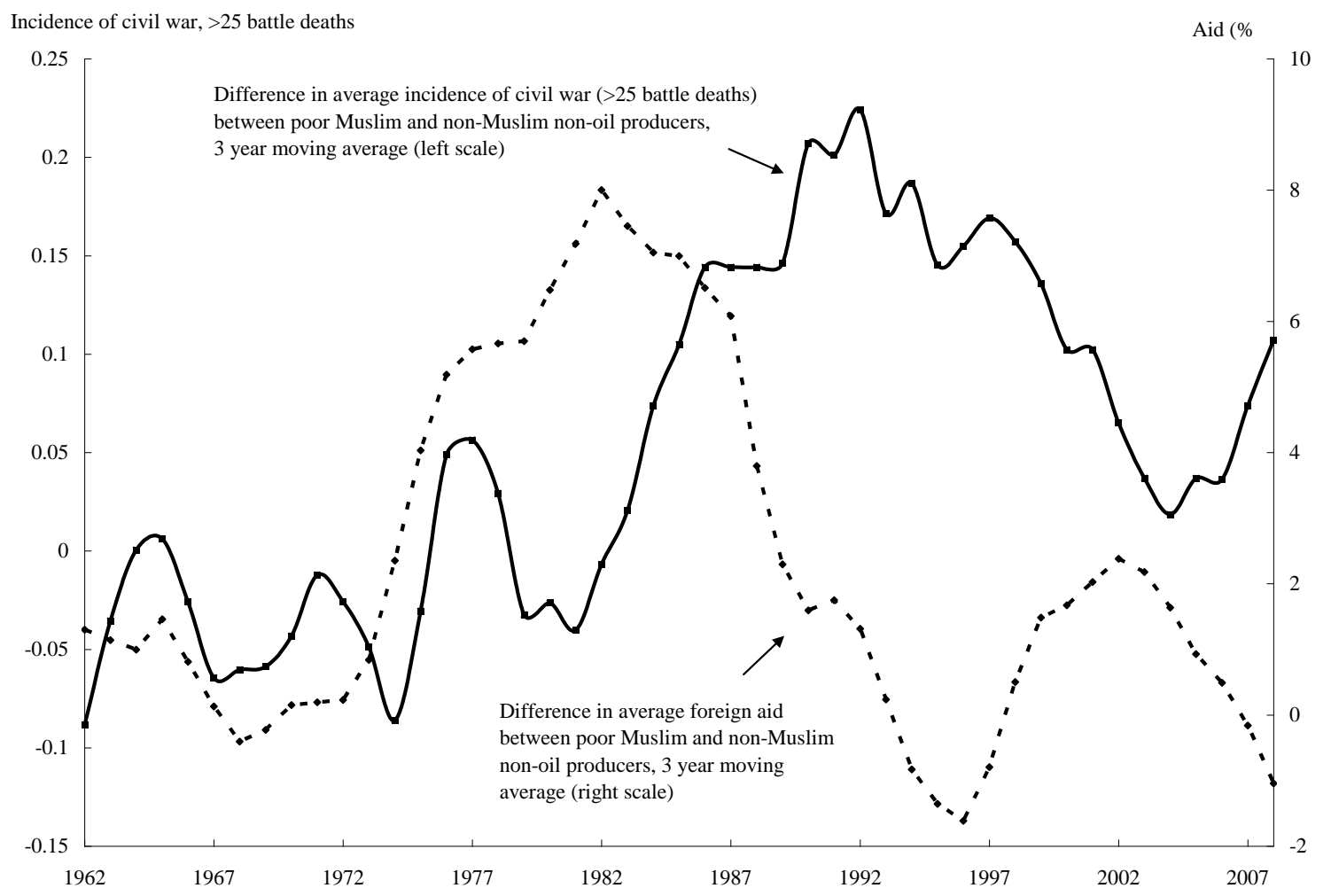




\section{Figure 7: The Muslim/Non-Muslim Foreign Aid and Conflict Differentials, Non-Oil Producers (at least 1,000 battle deaths per year)}

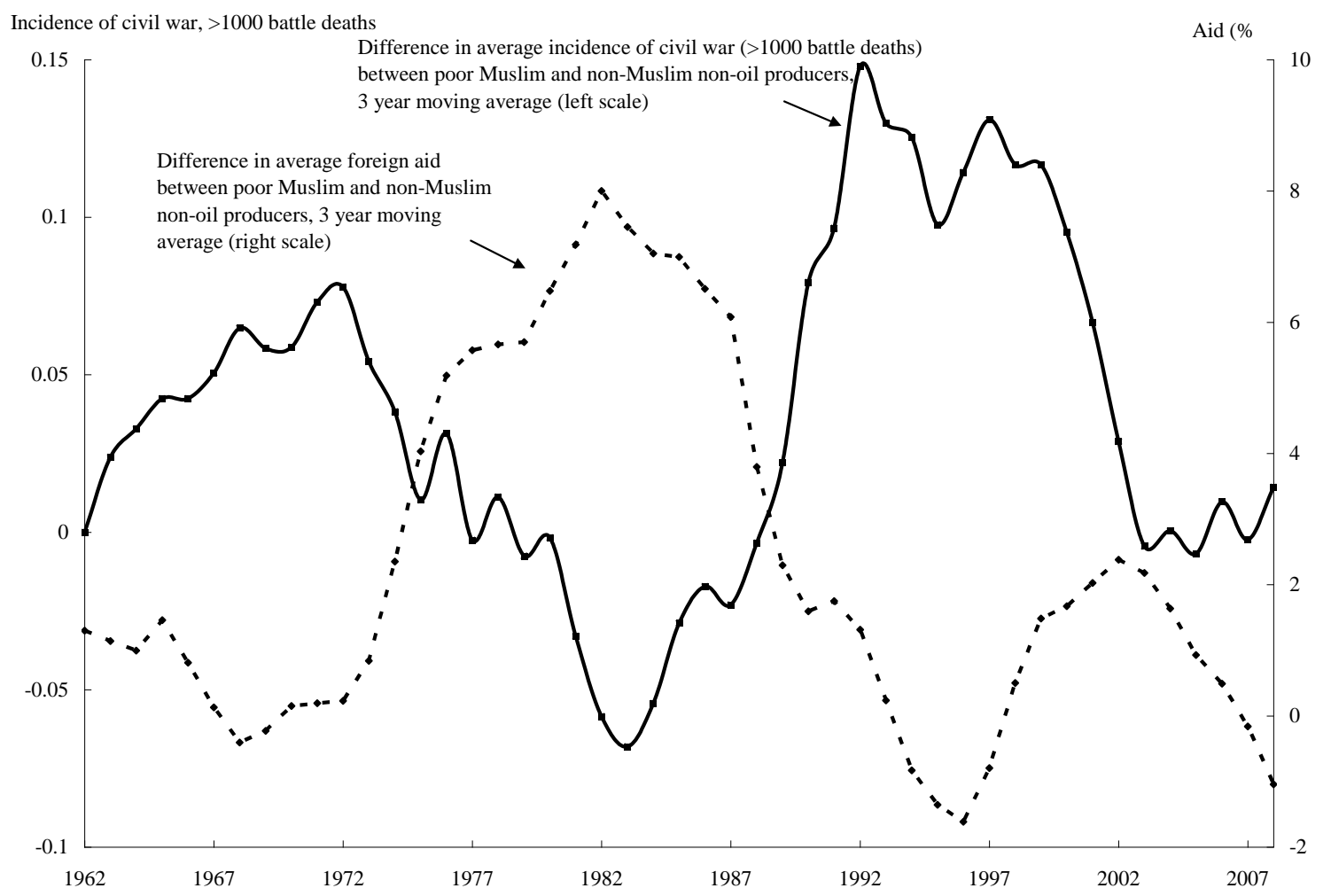

The differential effects of aid on political violence are large and statistically significant.

Table 3 presents difference-in-difference estimates for the incidence of civil war (panel A) and high intensity civil war (panel B) between periods of high and low oil prices and across Muslim and non-Muslim aid recipients. Our preferred estimates are those with high intensity civil war, as such conflict offers the strongest test of our propositions. Specifically, a 1,000 battle death threshold better captures the nature of mass violence involving an incumbent government and rebel groups. In many instances, the lower threshold of civil war measures one-sided violence, i.e. incumbent government killing rebels, or more often the case, a rebel group inflicting smallscale attacks against the government (that result in relatively low fatalities).

As Table 3 reveal, Muslim countries were approximately 5 percentage points more likely than non-Muslim countries to be experience high intensity civil conflict prior to the oil crisis of 1973. During the period of high oil prices, Muslim countries were 2 percentage points less likely than non-Muslim countries to be highly unstable. As the aid windfall went away, the propensity for major, two-sided violence jumped dramatically in Muslim countries: it was 9 percentage points more likely than in non-Muslim countries. 
Turning to the difference-in-difference estimates these imply that the aid windfall of 1973-1985 made Muslim countries 7 percentage points relatively more stable compared with the underlying propensity in non-Muslim countries. The end of the windfall engendered a relative rise in high intensity political violence as Muslim countries became 11 percentage points more likely to be engaged in two-sided violence, while non-Muslim countries became slightly more (around 1 percentage point) more stable. This effect is statistically significant. For the period after 2000, when higher oil prices prevailed, the propensity for high intensity civil war fell in Muslim countries (relative to the prior period), but they were as stable as non-Muslim countries.

Table 3: Civil War in Muslim and Non-Muslim Non-Oil Producers, by Periods of Low and High Oil Prices

Panel A

\begin{tabular}{lcccccc} 
Dependent variable: & \multicolumn{6}{c}{ Incidence of civil war (at least 25 battle deaths year) } \\
& Non-Muslim & Muslim & Difference & Std Error & Difference-in-difference & Std Error \\
\hline Before: 1960-1972 & 0.11 & 0.07 & -0.04 & {$[.061]$} & & \\
During: 1973-1985 & 0.15 & 0.20 & 0.05 & {$[0.075]$} & 0.09 & {$[0.079]$} \\
After: 1986-1999 & 0.17 & 0.33 & 0.16 & {$[0.084]^{*}$} & 0.11 & {$[0.095]$} \\
Post 2000: 2000-2008 & 0.11 & 0.18 & 0.07 & {$[0.067]$} & -0.09 & {$[0.060]$}
\end{tabular}

Panel B

Dependent variable:

Incidence of civil war (at least 1000 battle deaths per year)

\begin{tabular}{lcccccc} 
& Non-Muslim & Muslim & Difference & Std Error & Difference-in-difference & Std Error \\
\hline Before: 1960-1972 & 0.01 & 0.06 & 0.05 & {$[0.053]$} & & \\
During: 1973-1985 & 0.05 & 0.03 & -0.02 & {$[0.023]$} & -0.07 & {$[0.044]$} \\
After: 1986-1999 & 0.04 & 0.14 & 0.09 & {$[0.065]$} & 0.11 & {$[0.055]^{* *}$} \\
Post 2000: 2000-2008 & 0.02 & 0.03 & 0.01 & {$[0.027]$} & -0.08 & {$[0.051]^{\wedge}$}
\end{tabular}

Notes: Standard errors are clustered by country reported in brackets. ${ }^{\wedge}=$ significant at $15 \% ; *=$ significant at $10 \% ; * *=$ significant at $5 \%: * * *=$ significant at $1 \%$.

A potential concern with these findings is that factors unrelated to foreign aid disbursements could account for the differential conflict propensities across Muslim and nonMuslim non-oil producers. One such argument is the role of Cold War international politics. However, positing that the end of the Cold War can explain the rise in civil war misses the point of the treatment and control groups: one would have to argue that the end of the Cold War differentially affected instability in Muslim countries. Yet Cold War politics - in particular interventions by United States and the Soviet Union - did not discriminate on religion. Moreover, the rise of the two-sided violence began by the mid-1980s, well before the Cold War had ended. 
Another concern is that Muslim countries are inherently more prone to instability. The difference-in-difference research design essentially compares Muslim countries with themselves prior to losing the aid windfall (against the backdrop of non-Muslim countries). Thus, one would have to come up with an alternative explanation for why Muslim countries should suddenly become relatively more unstable right when the price of oil happened to fall if not through the budgetary effects of foreign aid.

Of course, there may be factors that are correlated with oil prices (but not necessarily with foreign aid) that may affect conflict propensity in poor, non-oil producing Muslim countries. Some of these plausible factors are the direct meddling of Gulf oil producers (e.g., Iran, Libya, Saudi Arabia) in the internal politics of Muslim recipients through the funding of Islamic extremism and rebel groups (Gilles 2002), and remittance inflows which might empower citizens to fight against the government. The results are robust to specifications and variables that plausibly capture these effects (e.g., control for number of assassinations, aggregate remittance inflows, etc.). We discuss these alternate explanations and our robustness checks in Appendix E.

Together, the trends in Tables 2 and 3 coupled with the findings linking oil prices and foreign aid from the Gulf oil producers are consistent with the core propositions underlying the political transfer problem. Moreover, the historically unique pattern of oil-price-induced foreign aid disbursements from Gulf oil producers provides a plausible account for the political development of poor, non-oil-producing Muslim aid recipients since the early 1970s. Yet as Figure 3 shows, the correlation between oil prices and aid breaks down around 2003. Unlike during the first high oil price period, aid receipts have not tracked the price of oil in the recent commodity price boom. As we explore next, this divergence in oil prices and government rents in non-oil producers suggests that the political transfer problem did not materialize in the post2003 commodity price boom. Indeed, this lack of a political transfer problem may have contributed to the closing of the democracy-autocracy gap between Muslim and non-Muslim non-oil producing countries in recent years. 


\section{Where did the Political Transfer Problem Go?}

Beginning around 2003, and driven by the accelerating demand from the rising prosperity in the developing world, the price of oil again began to rise, hitting a peak of $\$ 145$ per barrel in July 2008. The coffers of the oil producers were again flush with cash. Saudi Arabia's current account balance went from basically zero in 2002 to over $\$ 130$ billion in 2008 , or 28 percent of GDP according to IMF statistics, on the back of rising oil prices. The last time the Saudi current account surplus had topped the numbers of the late 2000s was in 1975. Kuwait was running a budget cash surplus of 20 percent of GDP. The Saudi government was literally building new cities out of the desert, spending $\$ 60$ billion to build four new "Economic Cities" for several million residents (SAGIA 2011).

And yet despite the windfall to the oil producers, the non-oil producing Muslim countries that experienced an aid windfall in the last high oil price would receive no such bonus this time around. The political transfer problem that appeared to characterize the first high oil price period so well might have been absent in the latest commodity price boom. Several hypotheses informed by the model appear to offer partial explanations for this change. One, with a larger population but the same sized resource endowment, the size of the windfall was effectively reduced-diminishing the need to give aid to shrink the prize for an insurgency. Two, the spread of sovereign wealth funds produced an alternative "technology" to shed excess windfall than by giving it away. Three, the world had simply grown richer, with better targeted aid programs, so whatever transfer problem might have occurred was simply washed out in the general equilibrium. Each of these hypotheses has some support in the data.

\section{Poor Rentiers}

After decades of population growth and civil unrest, the oil producers may have found themselves in a financial situation where they were too poor to be generous when the second oil price rise hit. By 2010, Saudi Arabia's population stood at over 27 million, more than four times that of the population in 1973, when the first oil crisis began. In our model, with population normalized to one, this would correspond to a decrease in $R$ which, all things equal, would reduce the threshold $Z$ that would trigger aid outflows. 
Meanwhile, GDP (in real terms) barely doubled. While at the aggregate levels exports, imports, and government spending have increased, these increases have not been enough to keep pace with the expanding population. As Table 4 shows, average annual exports and imports per capita during the second period of high oil prices were less than half of what they were from 1973-1985, and final government expenditure was similarly halved. So while the country may look like it is profiting just like the 1970s, the average Saudi citizen would not feel it in the same way.

Table 4: Per Capita Exports, Imports, and Government Expenditure in Saudi Arabia

\begin{tabular}{l|ccc} 
& Exports & Imports & $\begin{array}{c}\text { Final Government } \\
\text { Expenditure }\end{array}$ \\
\hline $1973-1985$ & $\$ 14,022$ & $\$ 7,771$ & $\$ 4,981$ \\
$1986-1999$ & $\$ 3,282$ & $\$ 2,949$ & $\$ 2,717$ \\
$2000-2009$ & $\$ 6,077$ & $\$ 3,404$ & $\$ 2,602$
\end{tabular}

Notes: Data compiled by authors from the World Development Indicators. Figures are in constant \$2000.

The inability of economic growth to keep pace with population growth in Saudi Arabia appears to be reflected in its diminishing aid program. Looking just at bilateral aid from Saudi Arabia, these numbers have been on a sharp decline since the first oil crisis (although multilateral aid from Arab countries has been much more steady). Average annual bilateral outgoing aid per Saudi in the last decade was less than one-seventh of what it was during the first oil crisis. From 2001-2009, Arab aid totaled about \$9 billion compared to over \$43 billion during the 1973-1985 period (all figures in 1973 dollars).

Accompanying the population growth in the Kingdom was a rise in dissent, particularly from the mid-1990s. During the 1970s, the Saudi regime seemed to rule the kingdom unchallenged with high oil revenues funding its welfare programs, although one particularly flagrant incident, the seizure of the Grand Mosque by religious extremists, would momentarily break the calm. Restlessness in the 1980s was limited to small leftist opposition organizations in the Eastern Province (Abir, 1993). Terrorist activity picked up in the latter half of the 1990s, though it still remained sporadic until May 2003, when al Qaeda began an active terror campaign, dramatically increasing the level at which the Kingdom's security forces had to operate. In 2004 alone, Saudi security forces captured more than 10 tons of drugs (that would be used to fund the terrorist activity), seized 2,000 weapons, and foiled almost 20,000 smuggling 
attempts, as well as gave a 25 percent pay increase to security and intelligence forces, indicative of an expensive expansion of its security program (Cordesman and Obaid, 2005). Additionally, the aftermath of September 11th led to increased operations for Saudi Arabia's security forces, as they arrested, detained, or questioned more than 2,500 individuals and worked to dismantle the major al Qaeda cells operating in the Kingdom. As civil unrest increased in the 2000s, more funds had to then be diverted to domestic expenditures in an attempt to ensure political stability (Marcoux and Shushan, 2011).

As the population and the level of civil unrest grew, it could mean that the safety valve of giving aid to poor countries was no longer required, as Saudi Arabia had grown poorer itself. However, these trends were more present in Saudi Arabia than in the other main oil-rich Arab countries, the United Arab Emirates and Kuwait. These countries have populations that are considerably smaller than Saudi Arabia's, although they too experienced demographic growth, but the net result is that Kuwait and the rich emirates were easily able to maintain their social and military spending domestically. While annual average per capita government spending continuously dropped over the time periods in Saudi Arabia, in Kuwait it increased from \$4,408 in $1973-1985$, to $\$ 4,728$ in $1986-1999$, to $\$ 5,091$ in $2000-2009$.

\section{From Charity to Savings?}

In Section 2, we posit that the aid programs of the oil producers can be explained by their desire to reduce the "prize" of capturing the state for a would-be insurgent. It seems that there would be more efficient modalities to protect funds from potential political rivals than just giving them away. In the last decade, one such modality has gained tremendously in salience. Sovereign wealth funds (SWFs) are a vehicle that countries have in parking their commodity windfalls out of reach from the normal budgetary process. Saving the excess windfall in a SWF could be a cheaper way to reduce the probability of conflict than giving it to other countries. In the model, introducing a SWF technology would be akin to introducing a special $D^{\prime}$ that expanded the budget envelope in a future period. If it could not be secured by an insurgent, it would trivially dominate the $D$ of foreign aid, and easily explain the end of the aid-oil relationship during the second period of high oil prices.

There is some evidence to suggest this hypothesis may be germane. In December 2011, there were an estimated $\$ 4.8$ trillion of assets under management at nearly 60 SWFs around the 
world (SWF Institute 2011; SWF assets are rarely made public, so the estimates should be taken with a grain of salt). Of those more than half were started in the new millennium, with the combined assets of the new funds worth over $\$ 1.2$ trillion. Not only was there a "noticeable pickup in the number of sovereign wealth funds set up around the world," noted Andrew Rozanov (2005), who allegedly coined the term, but there was a "particularly rapid pace of asset accumulation." Indeed, in 2005 Rosanov could identify only around \$1 trillion of assets under management in the SWFs. While some of the $\$ 4$ trillion difference over the last six years is due to identifying new SWFs and better estimating their assets, much is due to asset appreciation and new savings. For many countries, it seems non-controversial to conclude that the post-2000 round of current account surpluses got saved in SWFs at a higher rate than ever before.

However, there were some ten SWFs established by the mid-1970s, including those of Kuwait and Abu Dhabi, established in 1953 and 1976 respectively. In addition, the Saudis parked their excess earnings (and largely still do) in the central bank, the Saudi Arabian Monetary Authority (SAMA), which has been the de facto Saudi SWF since well before the first oil price shock. Thus, this alternative source to funnel excess oil rents does not appear to be a new concept for the primary Gulf oil-rich aid donors.

Because of the paucity of publically available data on SWFs, it is difficult to know whether they played a substantively larger role during the post-2003 oil price boom than during the 1973-95 period. That Saudi Arabia has not set up a meaningful sovereign wealth fund outside of SAMA ${ }^{13}$ actually gives us the opportunity to see how much of the oil wealth the country saved at different periods of time since the net foreign asset position of every central bank is reported to the IMF. We run a simple time series regression of the following formula:

$$
N F A_{\mathrm{t}}-N F A_{\mathrm{t}-1}=\mathbf{a}+\mathbf{b}^{*}\left(X_{\mathrm{t}}-I M_{\mathrm{t}}\right)+e_{\mathrm{t}}
$$

where $N F A_{\mathrm{t}}-N F A_{\mathrm{t}-1}$ is the change in net foreign assets and $X_{\mathrm{t}}-I M_{\mathrm{t}}$ is the trade surplus. The coefficient b will basically tell us what fraction of the trade surplus is "saved" in the central bank. It is not a metric that can be run blindly since the country may draw down on the reserves during years of net imports. In fact, this is close to what Saudi Arabia has done: it has allowed

\footnotetext{
${ }^{13}$ According to the SWF Institute, the Saudi Public Investment Fund, a true SWF founded in 2008, only had \$5.3 billion in December 2011, compared with $\$ 472.5$ billion in SAMA.
} 
the reserves to accumulate during years of high oil prices (and high net exports) and drawn down on them in the years of low oil prices (and low, but still positive, net exports).

We run equation (8) on Saudi time series data for the years 1973-95 as well as 20032009. During the first period, the coefficient on $\mathbf{b}$ is .73 and during the second period it is .90 , with standard errors of 0.10 and 0.19 respectively. ${ }^{14}$ This might be indicative of an internal trend of greater savings of excess oil revenues. However, this difference is not statistically significant, and the fact that Saudi Arabia has not changed the institutional arrangement of how funds are saved suggests that the second high oil price period has not presented a dramatically different new technology.

\section{What a Difference Three Decades Makes}

The last potential explanation of the end of the oil-aid relationship that we explore is the failing significance of oil in the global economy, and with it, oil donors in the world of foreign aid. Despite the extraordinary return of prices to their peaks of three decades before, by the 2000s oil was not as important — in the intervening decades, the world had gotten richer. The peak of the recent price run-up, 2008, brought oil consumption as a percentage of global GDP to 5 percent (Hodges, 2011); this was high, considering in 2003 it was just over 2 percent. But compared with the fuel bill in 1979 of 8 percent of GDP, the latest run-up has been fairly modest. Moreover, much of the expanding production has fallen in new producers outside of the traditional drillers. As a result, the wealth experienced by the Gulf producers in the late 2000s was not what it had been before.

To add, other donors have become slightly more generous and begun to target their aid to less repressive regimes. In 1973, the average OECD donor gave 0.34 percent of its GDP in foreign aid; by 2009, that figure had risen to 0.48. Meanwhile, as the above subsection described, Arab aid has become less generous over time. Moreover, we also noted in Section III that Muslim countries have historically had higher levels of repression as measured by executive constraints and political rights. Since the late 1990s, it has been fashionable among Western donors to tie aid to good policies (see World Bank 1998), as evidenced by the creation of the

\footnotetext{
${ }^{14}$ Data compiled from OPEC Annual Statistical Bulletins and the World Bank World Development Indicators. We also ran this for Kuwait and the United Arab Emirates. For Kuwait, the coefficients were 0.08 and 0.14 for the two periods; for the UAE, they were extremely noisy at 0.30 and -0.52 . These low (and variable) numbers are consistent with a greater role for the established and "off-balance sheet" SWFs in both countries.
} 
U.S. Millennium Challenge Account, which strictly targets countries on the political rights indicator we examine in Section III, among other indicators (Millennium Challenge Corporation 2011).

In Appendix F we test whether Western donors, those members of the OECD's Development Assistance Committee (DAC), increasingly target their aid to less repressive regimes. The results are consistent with the anecdotal evidence. Controlling for income of recipient country, under no decade is being less repressive (measured by a more constrained executive or higher political rights) correlated with more aid from DAC members except in the 2000s, which the coefficient became both statistically significant and substantively larger. Each point more repressive on both scales results in around seven tenths of a percent in GDP less total aid from DAC members, significant at the 5 percent level.

The net combination has been to undermine the potential impact from Gulf petrodollars being sent around the world in aid. Not only is less of a bonus being doled out by the Arab donors, but it is being counterbalanced by more aid being sent by Western donors to liberal regimes. Thus it should not be surprising that the relationship in Figure 3 between oil price and the Muslim-non-Muslim aid differential, so robust for so long, began to fail in 2003. Interestingly, however, the relationship in Figure 7 between the aid differential and conflict would not fail to hold; as the Muslim aid bonus disappeared by the end of our dataset in 2008, the Muslim conflict differential began to creep ominously up.

\section{Conclusion}

In this paper, we have argued for the theoretical possibility that autocrats experiencing a windfall in unearned income may find it optimal to donate some of the windfall away in order to make the state less attractive a prize to a potential insurgent. We put forward a simple model that makes that prediction, as well as the additional predictions that the recipients of the aid may themselves become more repressive with high aid and fall into conflict with lower levels of aid. We call these joint phenomena the political transfer problem, and argue that the largest windfall of the $20^{\text {th }}$ century, the period from 1973-85 during which oil prices were at all-time highs, produced political dynamics consistent with the model. Surprisingly, the political transfer problem did not seem to materialize when oil prices again began to creep up in the $21^{\text {st }}$ century; 
this nonexistence of the problem is easily, if convolutedly, explained by a number of explanations consistent with the model and with the evolution of geopolitics and economics.

Our model and empirical evidence provides a backdrop to understand some of the emerging dynamics underlying the political upheaval in the Middle East and North Africa this decade. On 17 December 2010, Tunisian Mohamed Bouazizi sets himself on fire, igniting what became known as the Arab Spring. By July 2012 Tunisia and Egypt had seen popular revolutions, Libya and Syria civil war, Yemen and Bahrain civil uprisings, and a dozen other countries protests of varying strength. Interestingly, none of these headline countries-with the potential exception of Libya, which, for its modern history has made a practice out of being an exception-fit our pattern of the oil-cursed rentier or the poor, aid-flooded but repressive recipient government. These countries were right in the middle: enough natural resource wealth and repression to provide the prize to fight over and a contemptible opponent, but not too much of either that an insurgency or revolution would be impossible. Furthermore, foreign aid in these countries (notably Egypt, Syria, Tunisia, and Yemen) was reaching its lowest levels in the past 40 years. ${ }^{15}$ In Egypt, foreign aid has fallen dramatically since 1990. In 1990, aid inflows comprised around 13 percent of GDP; by 2009 aid inflows amounted to less than 1 percent of GDP. Similarly, external rents received by Yemen declined: from 8.3 percent of GDP in 1990 to around 1 percent of GDP in 2009.

In most cases of regime change in the Arab Spring, the political activity was largely peaceful, and thus did not even lead to the 1000 battle deaths necessary to qualify as two-sided conflict in our dataset. But a moment happened, for so many reasons, which made the lingering autocracy of these countries a target. Decades after they might have-in the absence of the political transfer problem - these countries made rapid steps toward democratization, bringing the average level of democracy in Muslim countries that much closer to the average level in nonMuslim countries, which (among non oil-producers) had last been equal in 1975.

\footnotetext{
${ }^{15}$ Figure G1 in Appendix G presents the trends of aid inflows from 1972-2009 in Egypt, Syria, Tunisia, and Yemen.
} 


\section{References}

Abir, Mordechai. 1993. Saudi Arabia: Government, Society and the Gulf Crisis, London: Routledge.

Adam, Hussein M. 1999. "Somali Civil Wars." In Civil Wars in Africa: Roots and Resolution. eds. Taisier M. Ali and Robert O. Matthews. Montreal: McGill-Queen's University Press.

Ahmed, Faisal Z. 2012. “The Perils of Unearned Foreign Income: Aid, remittances, and government survival”, American Political Science Review, 106(1): 146-165

Auty, R.M. "Introduction and overview" in Auty, R.M. (Ed.), Resource Abundance and Economic Development, Oxford: Oxford University Press, pp. 3-18.Banks, Arthur S. 2010. Banks Cross-National Time Series Data Archive. [Computer file]. Jerusalem: Databanks International. URL: http://www.databanks.sitehosting.net/

Besley, Timothy and Torsten Persson. 2009. "The Origins of State Capacity: Property Rights, Taxation and Politics," American Economic Review, 99(4), 1218-44.

Besley, Timothy and Torsten Persson. 2010. "State Capacity, Conflict and Development," Econometrica, 78, 1-34.

Besley, Timothy and Torsten Persson. 2011a. "The Logic of Political Violence," Quarterly Journal of Economics: 126(3), 1411-1445.

Besley, Timothy and Torsten Persson. 2011b. "Fragile States and Development Policy," Journal of the European Economic Association, 9 (3): 371-398.

Besteman, Catherine. 1996. "Violent politics and the politics of violence: the dissolution of the Somali nation-state.” American Ethnologist. 23 (3), 579-596.

Brakman, Steven and Charles van Marrewijk. 1998. The Economics of International Transfers. Cambridge, UK: Cambridge University Press.

Caselli, Francesco and Andrea Tesei. 2011. "Resource Windfalls, Political Regimes, and Political Stability.” Mimeo: London School of Economics.

Collier, Paul. 2007. The Bottom Billion: Why the Poorest Countries are Failing and What can be Done About it. Oxford University Press, Oxford.

Collier, Paul, Lani Elliot, Havard Hegre, Anke Hoeffler, Marta Reynal-Querol, and Nicholas Sambanis. 2003. Breaking the Conflict Trap: Civil War and Development Policy. Oxford: Oxford University Press and Washington, D.C: The World Bank.

Coller, Paul and Anke Hoeffler. 2002. "Aid, Policy and Peace: Reducing the risks of civil conflict," Defense and Peace Economics, 13 (6): 435-450.

Corden W.M. and J.P. Neary. 1982. "Booming Sector and De-Industrialisation in a Small Open Economy,” The Economic Journal, 92 (December): 825-848. 
Cordesman, Anthony and Nawaf Obaid. 2005. National Security in Saudi Arabia: Threats, Responses, and Challenges, Westport, CT: Praeger Security International.

Freedom House. 2011. "Freedom in the World Country Ratings, 1972-2011", available: www.freedomhouse.org, accessed: 9/16/2011

Gleditsch, Nils Petter, Peter Wallensteen, Mikael Eriksson, Margareta Sollenberg and Havard Strand. 2002. "Armed Conflict 1946-2001: A New Dataset", Journal of Peace Research, 39(5): 615-637.

Gleditsch, Kristian S. and Michael D. Ward. 1997. "Double Take: A Re-Examination of Democracy and Autocracy in Modern Polities." Journal of Conflict Resolution, 41: 361-383.

Harbom, Lotta, Eric Melander and Peter Wallensteen. 2008. "Dyadic Dimensions of Armed Conflict, 1946-2008", Journal of Peace Research, 45(5): 697-710.

Hallwood, Paul and Stuart Sinclair. 1981. Oil, Debt \& Development: OPEC in the Third World. London: George Allen \& Unwin Ltd.

Hodges, Paul. 2011. "Global oil bill now 5\% of GDP," ICIS blog: Chemicals and the Economy. Oct 12, 2011, URL: http://www.icis.com/blogs/chemicals-and-the-economy/2011/10/global-oilcosts-now-over-5-of.html, accessed Jan 32012.

Hunter, Shireen. 1984. OPEC and the Third World: the politics of aid. London: Croom Helm. Kepel, Gilles. 2002. Jihad: The Trail of Political Islam, trans. Anthony F. Roberts. Cambridge, MA: Harvard University Press.

Keynes, John M. 1929. “The German Transfer Problem.” The Economic Journal, 39 (153): 1-7.

Kiros, Azariah. 2007. "Sweden Cuts Foreign Aid Recipients." Radio Sweden, Aug 31: http://www.networkeurope.org/feature/sweden-cuts-foreign-aid-recipients

Maddison, Angus. 2010. "Statistics on World Population, GDP and Per Capita GDP, 1-2008 AD," dataset, available on http://www.ggdc.net/MADDISON/oriindex.htm, accessed 4 Jan 2012. Mahdavy, Hossein. 1970. "The Patterns and Problems of Economic Development in Rentire States: The Case of Iran." In Studies in Economic History of the Middle East from the Rise of Islam to the Present Day, ed. M.A. Cook. Oxford: Oxford University Press.

Marshall, Monty G., Keith Jaggers, and Ted Robert Gurr. 2010. PolityIV Dataset [Computer file; version p4v2010] College Park, MD: Center for International Development and Conflict Management, University of Maryland.

Miguel, Edward, Shankar Satyanath, and Ernest Sergenti. 2004. "Economic Shocks and Civil Conflict: An Instrumental Variables Approach”, Journal of Political Economy, 112(4): 725-753.

Millennium Challenge Corporation. 2011. "Report on the Criteria and Methodology for Determining the Eligibility of Candidate Countries for Millennium Challenge Account 
Assistance in Fiscal Year 2012." URL: https://www.mcc.gov/documents/reports/report2011001066201-fy12-selection-criteria.pdf, accessed 5 Jan 2012.

Neumayer, Eric. 2002. "Arab-Related Bilateral and Multilateral Sources of Development

Financing: Issues, Trends, and the Way Forward." United Nations University: World Institute for Development Economics Research Discussion Paper No. 2002/96. October 2002.

Neumayer, Eric. 2003. "What Factors Determine the Allocation of Aid by Arab Countries and Multilateral Agencies?” Journal of Development Studies. 39 (4): 134-147

Nunn, Nathan and Nancy Qian. 2010. "Aiding Conflict: The Unintended Consequences of U.S. Food Aid on Civil War," Mimeo: Harvard University.

OECD. 2006. DAC Guidelines and Reference Series Applying Strategic Environmental Assessment: Good Practice Guidance for Development Co-operation. OECD: Paris.

Patrick, Stewart. 2007. "'Failed' States and Global Security: Empirical Questions and Policy Dilemmas," International Studies Review 9: 644-662.

Ragan, Ragu and Arvind Subramanian. 2011. "Aid, Dutch Disease, and Manufacturing Growth," Journal of Development Economics. 94 (1): 106-118.

Robinson, James A., Ragnar Torvik, and Thierry Verdier. 2006. "Political foundations of the resource curse," Journal of Development Economics, 79: 447-468.

Rosanov, Andrew. 2005. "Who Holds the Wealth of Nations?" Central Banking Journal, May 2005.

Sach, Jeffrey D. and Andrew M. Warner. 1995. "Natural Resource Abundance and Economic Growth." NBER Working Paper 5398.

Saudi Arabian General Investment Authority (SAGIA). 2011. "Economic Cities," URL: http://www.sagia.gov.sa/en/Why-Saudi-Arabia/Economic-cities/ accessed 26 Dec 2011.

Sovereign Wealth Fund (SWF) Institute. 2011. "Sovereign Wealth Fund Rankings," URL: http://www.swfinstitute.org/fund-rankings/ accessed 26 Dec 2011.

Stewart, Frances and Graham Brown. 2010. "Fragile States: CRISE Overview 3." Centre for Research on Inequality, Human Security and Ethnicity (CRISE), Oxford.

Sumner, Andy. 2011. "How will more UK aid reduce poverty in fragile, corrupt and 'non-free' places?" Global Dashboard, Apr 7: http://www.globaldashboard.org/2011/04/07/will-more-ukaid-reduce-poverty-in-fragile-corrupt-and-non-free-places/

Svensson, Jakob. 2000. "Foreign aid and rent-seeking," Journal of International Economics, 51 (2), August 2000, 437-461.

Werker, Eric D., Faisal Z. Ahmed, and Charles Cohen. 2009. "How is aid spent? Evidence from a natural experiment," American Economic Journal - Macroeconomics, 1(2): 225-244. 
Werker, Eric D. 2012. "The Political Economy of Bilateral Foreign Aid.” In Encyclopedia of Financial Globalization. Oxford: Elsevier (forthcoming).

World Bank. 1998. Assessing Aid. What Works, What Doesn't, and Why. New York: Oxford University Press.

Zoellick, Robert. 2009. "Fragile States: Securing Development," Survival, 50 (6): 67-84. 


\section{Appendix A: Proofs of Model}

\section{Proof of Proposition 1:}

Proof. To determine when peace is a better response to peace than low violence, we compare the utility functions for the two. $A^{I n c}(0)=0$ is preferred to $A^{I n c}(0)=A_{L}^{I n c}$ if $V^{I n c}(w, R ; D, 0,0) \geq$ $V^{I n c}\left(w, R ; D, 0, A_{L}^{I n c}\right)$, which is equivalent to:

$$
[(1-\Theta)-\gamma(0,0)(1-2 \Theta)][Z-0] \geq\left[(1-\Theta)-\gamma\left(0, A_{L}^{I n c}\right)(1-2 \Theta)\right]\left[Z-A_{L}^{I n c}\right]
$$

or

$$
Z \leq\left[(1-\Theta)-\gamma\left(0, A_{L}^{I n c}\right)(1-2 \Theta)\right] A_{L}^{I n c} /\left[(1-2 \Theta)\left(\gamma(0,0)-\gamma\left(0, A_{L}^{I n c}\right)\right)\right] \equiv Z^{I n c}\left(0 ; 0, A_{L}^{I n c}\right)
$$

Similarly, peace is a better response to peace than high violence (i.e., $A^{\operatorname{Inc}}(0)=0$ is preferred to $\left.A^{\text {Inc }}(0)=A_{H}^{\text {Inc }}\right)$ if

$$
Z \leq\left[(1-\Theta)-\gamma\left(0, A_{H}^{I n c}\right)(1-2 \Theta)\right] A_{H}^{I n c} /\left[(1-2 \Theta)\left(\gamma(0,0)-\gamma\left(0, A_{H}^{I n c}\right)\right)\right] \equiv Z^{I n c}\left(0 ; 0, A_{H}^{I n c}\right) .
$$

Note that a higher level is always preferred by the incumbent for a sufficiently high $Z$ and a lower level of violence is always preferred for a sufficiently low $Z$, and there is never switching back and forth between violence levels as $Z$ increases (holding opposition violence constant). Thus, peace is the best response to peace if both conditions are met, or $\hat{A}^{I n c}(0)=0$, if

$$
Z \leq \min \left\{Z^{I n c}\left(0 ; 0, A_{L}^{I n c}\right), Z^{I n c}\left(0 ; 0, A_{H}^{I n c}\right)\right\}
$$

If the first threshold in (*) is less than or equal to the second, then there exist value(s) of $Z$ for which $\hat{A}^{I n c}(0)=A_{L}^{I n c}$. This would be true because the threshold for switching to high violence is higher than the threshold for switching to low violence, which is labeled case (i). If that is the case, then high violence is the optimal response against peace (i.e., $\hat{A}^{\text {Inc }}(0)=A_{H}^{\text {Inc }}$ ) whenever $A^{I n c}(0)=A_{H}^{I n c}$ is preferred to $A^{I n c}(0)=A_{L}^{I n c}$ (which will imply that it is preferred to $\left.\hat{A}^{I n c}(0)=0\right)$. This happens when 


$$
\begin{gathered}
Z>\left(\left[(1-\Theta)-\mathrm{\gamma}\left(0, A_{H}^{I n c}\right)(1-2 \Theta)\right] A_{H}^{I n c}-\left[(1-\Theta)-\mathrm{\gamma}\left(0, A_{L}^{I n c}\right)(1-2 \Theta)\right] A_{L}^{I n c} /[(1-2 \Theta)(\mathrm{\gamma}(0,\right. \\
\left.\left.\left.A_{L}^{I n c}\right)-\mathrm{\gamma}\left(0, A_{H}^{I n c}\right)\right)\right] \equiv Z^{I n c}\left(0 ; A_{L}^{I n c}, A_{H}^{I n c}\right) .
\end{gathered}
$$

When $Z^{I n c}\left(0 ; 0, A_{L}^{I n c}\right)<Z<Z^{I n c}\left(0 ; 0, A_{H}^{I n c}\right)$, low violence is the best response to peace (so $\hat{A}^{I n c}(0)$ $\left.=A_{L}^{I n c}\right)$. This covers case (i).

If the second expression in $\left(^{*}\right)$ is larger, then $\hat{A}^{I n c}(0) \neq A_{L}^{I n c}$ for all $Z$. The reason this happens is that as $Z$ increases from zero, it passes the threshold which makes high violence desirable against peace before it passes the threshold that makes low violence desirable. As $Z$ continues to get larger, high violence continues to be more attractive by a greater margin over low violence. Up to $Z^{I n c}\left(0 ; 0, A_{H}^{I n c}\right), \hat{A}^{I n c}(0)=0$, and then above $Z^{I n c}\left(0 ; 0, A_{H}^{I n c}\right), \hat{A}^{I n c}(0)=A_{H}^{I n c}$, which is case (ii).

The analysis of $\hat{A}^{I n c}\left(A_{L}^{O p p}\right)$ is simpler, because we have assumed that it is impossible to have an undefended insurgency. Following the same logic as above, the optimal response against opposition violence is to use high violence (i.e., $\left.\hat{A}^{I n c}\left(A_{L}^{O p p}\right)=A_{H}^{I n c}\right)$ if

$$
\begin{gathered}
Z>\left(\left[(1-\Theta)-\gamma\left(A_{L}^{O p p}, A_{H}^{I n c}\right)(1-2 \Theta)\right] A_{H}^{I n c}-\left[(1-\Theta)-\gamma\left(A_{L}^{O p p}, A_{L}^{I n c}\right)(1-2 \Theta)\right] A_{L}^{I n c} /\right. \\
{\left[(1-2 \Theta)\left(\gamma\left(A_{L}^{I n c}, A_{L}^{I n c}\right)-\gamma\left(A_{L}^{I n c}, A_{H}^{I n c}\right)\right)\right] \equiv Z^{I n c}\left(A_{L}^{O p p} ; A_{L}^{I n c}, A_{H}^{I n c}\right) .}
\end{gathered}
$$

Thus, holding the opposition violence constant, incumbent violence is non-decreasing in $Z$, and we can pinpoint the threshold at which violence changes. Also, for sufficiently low values of $Z$, the optimal response to peace is peace and the optimal response to violence is the lower level of violence. For sufficiently high values of $Z$, the optimal response is high violence. $\square$

\section{Proof of Proposition 2:}

Proof. $Z^{I n c}\left(A_{L}^{O p p} ; A_{L}^{I n c}, A_{H}^{I n c}\right)$ is the level of $Z$ at which the incumbent is indifferent between using high and low violence, given that the opposition uses violence. If $Z$ moves above $\mathrm{Z}^{\mathrm{Inc}}\left(A_{L}{ }^{O p p} ; A_{L}^{I n c},{A_{H}}^{\text {Inc }}\right)$, then suddenly opposition violence will be met with high violence, and this is the only value of $Z$ where an increase in $Z$ can cause opposition violence to become unattractive. 
Consider $Z_{1}$ and $Z_{2}$, with $Z_{1}<Z_{2}$ and $Z^{I n c}\left(A_{L}^{O p p} ; A_{L}^{I n c}, A_{H}^{I n c}\right)$ not $\epsilon\left[Z_{1}, Z_{2}\right]$. We define $\hat{A}^{o p p}\left(Z_{\mathrm{j}}\right)$ as the optimal violence for the opposition given $Z=Z_{j}$ and $\hat{A}^{\text {Inc }}\left(\hat{A}^{O p p}\left(Z_{j}\right)\right)$ to be the corresponding violence level for the incumbent. Since we are trying to show that $\hat{A}^{o p p}$ is nondecreasing, we can assume that $\hat{A}^{O p p}\left(Z_{1}\right)=A_{L}^{O p p}$ (otherwise it is trivially non-decreasing), and it is sufficient to show that $\hat{A}^{O p p}\left(Z_{2}\right)=A_{L}^{O p p}$. We define $\hat{A}^{O p p}\left(A_{\text {peace }}^{\text {Inc }}, A_{\text {fight }}^{\text {Inc }}\right)$ as the opposition's optimal violence given that the incumbent will use $A^{I n c}{ }_{\text {peace }}$ if the opposition uses zero violence and $A_{f i g h t}^{I n c}>0$ if they use $A_{L}{ }^{O p p}$. We are interested in characterizing when the opposition will choose violence, given that the incumbent responds optimally—that is, when $A^{O p p}\left(\hat{A}^{I n c}(0)\right.$, $\left.\hat{A}^{I n c}\left(A_{L}^{O p p}\right)\right)=A_{L}^{O p p}$ is preferred to $A^{O p p}\left(\hat{A}^{I n c}(0), \hat{A}^{I n c}\left(A_{L}^{O p p}\right)\right)=0$. This holds when the opposition's utility is higher under violence, $V^{O p p}\left(w, R ; D, 0, \hat{A}^{I n c}(0)\right)<V^{O p p}\left(w, R ; D, A_{L}^{O p p}\right.$, $\left.\hat{A}^{I n c}\left(A_{L}^{O p p}\right)\right)$. Note that the opposition would never use violence when $\gamma\left(A_{L}^{O p p}, \hat{A}^{I n c}\left(A_{L}^{O p p}\right)\right) \leq \mathrm{\gamma}(0$, $\hat{A}^{I n c}(0)$ ), because then using violence would not increase their chances of coming to power. Substituting in for the utility function, the opposition uses violence when $\mathrm{\gamma}\left(A_{L}^{O p p}, \hat{A}^{I n c}\left(A_{L}{ }^{O p p}\right)\right)>$ $\gamma\left(0, \hat{A}^{\text {Inc }}(0)\right)$ and

$$
\begin{gathered}
(1-0)+\left[\Theta+\gamma\left(0, \hat{A}^{I n c}(0)\right)(1-2 \Theta)\right] 2\left[Z-\hat{A}^{I n c}(0)\right]<\left(1-A_{L}^{O p p}\right)+\left[\Theta+\gamma\left(A_{L}^{O p p}, \hat{A}^{I n c}\left(A_{L}{ }^{O p p}\right)\right)(1-\right. \\
2 \Theta)] 2\left[Z-\hat{A}^{I n c}\left(A_{L}{ }^{O p p}\right)\right]
\end{gathered}
$$

or

$$
\begin{gathered}
Z>\left(\left(A_{L}^{O p p} / 2\right)+\left[\Theta+\gamma\left(A_{L}^{O p p}, \hat{A}^{I n c}\left(A_{L}^{O p p}\right)\right)(1-2 \Theta)\right] \hat{A}^{I n c}\left(A_{L}^{O p p}\right)-\left[\Theta+\gamma\left(0, \hat{A}^{I n c}(0)\right)(1-2 \Theta)\right]\right. \\
\left.\hat{A}^{I n c}(0)\right) /\left((1-2 \Theta)\left(\gamma\left(A_{L}^{O p p}, \hat{A}^{I n c}\left(A_{L}^{O p p}\right)\right)-\gamma\left(0, \hat{A}^{I n c}(0)\right)\right)\right) \equiv Z^{T}(Z)
\end{gathered}
$$

Note that $Z^{T}$ is itself a function of $Z$, because the values of $\hat{A}^{I n c}(0)$ and $\hat{A}^{I n c}\left(A_{L}{ }^{O p p}\right)$ depend on $Z$. By assumption, $A^{O p p}\left(\hat{A}^{I n c}(0), \hat{A}^{I n c}\left(A_{L}{ }^{O p p}\right)\right)=A_{L}^{O p p}$ is optimal when $Z=Z_{1}$, so the inequality (**) holds at $Z_{1}$. By the previous proposition, if $Z$ is increased to $Z_{2}$, it must be the case that neither $\hat{A}^{I n c}(0)$ nor $\hat{A}^{I n c}\left(A_{L}{ }^{O p p}\right)$ has decreased because both expressions are nondecreasing in $Z$. Also, $\hat{A}^{I n c}\left(A_{L}{ }^{O p p}\right)$ has not increased because we have not crossed over $Z^{I n c}\left(A_{L}{ }^{O p p} ; A_{L}^{I n c}, A_{H}^{I n c}\right)$, the only value for which $\hat{A}^{I n c}\left(\mathrm{~A}_{\mathrm{L}}{ }^{\mathrm{Opp}}\right)$ can increase. Thus, $\hat{A}^{I n c}\left(A_{L}{ }^{\text {Opp }}\right)$ has not changed, and neither has $\gamma\left(A_{L}^{O p p}, \hat{A}^{I n c}\left(A_{L}^{O p p}\right)\right) . \hat{A}^{I n c}(0)$ has increased or stayed the same, which implies that $\mathrm{\gamma}\left(0, \hat{A}^{I n c}(0)\right)$ has decreased or stayed the same because $y$ (the probability of power changing hands) is decreasing 
in the second argument (incumbent violence). If $\hat{A}^{\text {Inc }}(0)$ increases, the direct effect is to cause the threshold in (**) $Z^{T}$ to get smaller, and if $\mathrm{\gamma}\left(0, \hat{A}^{\text {Inc }}(0)\right)$ decreases, that also causes the threshold to get smaller (because the denominator increases). Therefore, increasing $Z$ from $Z_{1}$ to $Z_{2}$ does not increase $Z^{T}$, so if the inequality in (**) is satisfied at $Z_{1}$ then it must also be satisfied at $Z_{2}$, and opposition violence is nondecreasing.

Finally, it is straightforward to show that for sufficiently low and high $Z$ the opposition is peaceful and violent, respectively. For a very low $Z$, the incumbent will respond peacefully against peace. If $Z$ is small enough, then using violence must be wasteful for the opposition. For a very high $Z$, the incumbent is guaranteed to use maximum violence. If $Z$ is large enough, the prize is sufficiently enticing to induce opposition violence. $\square$

\section{Proof of Lemma 1:}

Proof. We know from Proposition 1 that for sufficiently high values of $Z$, the incumbent will use high violence regardless of the opposition's choice. In that case, the opposition can increase their chance of gaining power by using violence rather than peace; there is a sufficiently high $Z$ that will cause the opposition to fight. Also, for a sufficiently low $Z$, the prize is so small that fighting will be counterproductive.

Define $P$ as the set of $Z$ 's for which the opposition is peaceful. $P$ can take one of two forms, depending on whether opposition violence decreases at $Z^{I n c}\left(A_{L}{ }^{O p p} ; A_{L}^{I n c}, A_{H}^{I n c}\right)$. If it does not (case (a)), then $P=[0, q]$. We know from proposition 2 that opposition violence never decreases, and that there is peace for $Z=0$ and there is violence for sufficiently high $Z$, so the only thing left to verify is that at $q$, there is peace. There are two ways for the opposition to use violence just above $q$ and peace just below $q$. The first is that the incumbent's strategy stays the same as we cross $q$, but the opposition responds differently to those choices. In that case, at $q$, the opposition is indifferent to peace or violence, and by assumption uses peace. The other possibility is that the incumbent crosses an indifference point defined in Proposition 1: $Z^{I n c}(0 ; 0$, $\left.A_{L}^{I n c}\right), Z^{I n c}\left(0 ; 0, A_{H}^{I n c}\right)$, or $Z^{I n c}\left(0 ; A_{L}^{I n c}, A_{H}{ }^{I n c}\right)$. If that happens then the incumbent uses lower violence when indifferent - which implies that peace is attractive to the opposition at $q$, which again implies that $q \in P$. Crossing the threshold $Z^{I n c}\left(A_{L}{ }^{O p p} ; A_{L}^{I n c}, A_{H}^{I n c}\right)$ never causes the opposition to become violent. 
If opposition violence does decrease at $Z^{I n c}\left(A_{L}^{O p p} ; A_{L}^{I n c}, A_{H}{ }^{I n c}\right)$, then $P$ will be the union of two intervals (case (b)). We still know that there is peace for $Z=0$ and violence for sufficiently high values of $Z$. We know that the only decrease in violence occurs at $Z^{I n c}\left(A_{L}{ }^{O p p} ; A_{L}^{I n c}, A_{H}^{I n c}\right)$, and that the incumbent will be using high violence in response to low violence by assumption. Now $P=[0, r] \mathrm{U}\left(Z^{I n c}\left(A_{L}^{O p p} ; A_{L}^{I n c}, A_{H}^{I n c}\right), s\right]$ for some real numbers $r$ and $s$. By the same argument as above, there must be peace for values of $Z$ equal to $r$ and $s$.

If case (a) applies, then $D^{\text {min }}$, the minimum value of aid that will induce peace from the incumbent, is $\max \{0, w(Z-q)\} . D^{\min }$ is 0 if there is already peace, and if there is not, giving aid of $w(Z-q)$ will reduce $Z$ to $q$ (recall that $Z=(R-D) / w$ ) and cause peace. If case (b) applies, then if $Z \in P$ then $D^{m i n}=0$. If $Z>s$ then $D^{\text {min }}=w(Z-s)$. If $Z \in\left(r, Z^{I n c}\left(A_{L}{ }^{O p p} ; A_{L}^{I n c}, A_{H}{ }^{I n c}\right)\right]$, then $D^{\min }=w(Z-r)$.

Proof of Proposition 3:

Proof. Recall the utility functions,

$$
V^{I n c}\left(w, R ; D, A^{O p p}, A^{I n c}\right)=w+\left[(1-\Theta)-\gamma\left(A^{O p p}, A^{I n c}\right)(1-2 \Theta)\right] 2\left[R-D-w A^{I n c}\right]
$$

and

$$
V^{O p p}\left(w, R ; D, A^{O p p}, A^{I n c}\right)=w\left(1-A^{O p p}\right)+\left[\Theta+\gamma\left(A^{O p p}, A^{I n c}\right)(1-2 \Theta)\right] 2\left[R-D-w A^{I n c}\right] .
$$

Suppose the incumbent chooses aid $\widehat{D}>0$ and the opposition uses violence $A_{L}{ }^{O p p}>0$. This will lead to a contradiction. The incumbent is optimizing, so the incumbent's payoff is better when giving aid rather that not giving aid (assuming that the opposition and incumbent both choose violence optimally after the aid choice). In symbols,

$$
V^{I n c}\left(w, R ; \widehat{D}, A_{L}^{O p p}, \hat{A}^{I n c}\left(A_{L}^{O p p}, \widehat{D}\right)\right)>V^{I n c}\left(w, R ; 0, \hat{A}^{O p p}(0), \hat{A}^{I n c}\left(\hat{A}^{O p p}(0), 0\right)\right)
$$

where $\hat{A}^{O p p}(0)$ is the opposition's optimal violence in response to 0 aid and $\hat{A}^{I n c}\left(\hat{A}^{O p p}(0), 0\right)$ is the incumbent's optimal violence in response to the opposition's choice and knowing $D=0$. But if that is true, then we know 


$$
\begin{gathered}
V^{I n c}\left(w, R ; \widehat{D}, A_{L}^{O p p}, \hat{A}^{I n c}\left(A_{L}^{O p p}, \widehat{D}\right)\right)> \\
V^{I n c}\left(w, R ; 0, \hat{A}^{O p p}(0), \hat{A}^{I n c}\left(\hat{A}^{O p p}(0), 0\right)\right) \geq \\
V^{I n c}\left(w, R ; 0, \hat{A}^{O p p}(0), \hat{A}^{I n c}\left(A_{L}^{O p p}, \widehat{D}\right) \geq\right. \\
V^{I n c}\left(w, R ; 0, A_{L}^{O p p}, \hat{A}^{I n c}\left(A_{L}^{O p p}, \widehat{D}\right)\right)
\end{gathered}
$$

The first inequality is just a restatement. The second inequality holds because the incumbent cannot be made better off by choosing what is potentially the wrong violence level; i.e., $\hat{A}^{I n c}\left(\hat{A}^{O p p}(0), 0\right)$ is the correct violence level because it responds to the true conditions while $\hat{A}^{I n c}\left(A_{L}{ }^{O p p}, \widehat{D}\right)$ is a potentially incorrect level. The third holds because the incumbent cannot be made better off by changing the opposition's violence level to $A_{L}^{O p p}$ away from $\hat{A}^{O p p}(0)$, which is the opposition's optimal violence given that there is zero aid. Changing the opposition's violence level to $A_{L}{ }^{O p p}$ cannot be an improvement because that change reduces the chance of holding power. Comparing the fourth term to the first gives a contradiction: the incumbent cannot be made better off by giving aid when everything else is held constant.

\section{Proof of Lemma 2:}

Proof. Suppose the proposition is false for another contradiction, meaning $\widehat{D} \neq 0$ and $\widehat{D} \neq D^{\min }$. $\widehat{D}$ is optimal, so from the previous proposition, $\hat{A}^{O p p}(\widehat{D})=0$, meaning that the opposition will not use violence if incumbent give aid equal to $\widehat{D}$. $D^{\text {min }}$ is the lowest aid level that generates opposition peace, so $\widehat{D}>D^{\min }$. But this leads to a contradiction:

$$
V^{I n c}\left(w, R ; \widehat{D}, 0, \hat{A}^{I n c}(0, \widehat{D})\right) \geq V^{I n c}\left(w, R ; D^{\min }, 0, \hat{A}^{I n c}(0, \widehat{D})\right)
$$

because $\widehat{D}$ is the optimal aid and $\hat{A}^{I n c}(0, \widehat{D})$ is the optimal violence, given that aid was $\widehat{D}$ and opposition violence was zero. But in $V^{I n c}$, aid enters only negatively when all of the other variables are held constant. That implies:

$$
V^{I n c}\left(w, R ; \widehat{D}, 0, \hat{A}^{I n c}(0, \widehat{D})\right)<V^{I n c}\left(w, R ; D^{m i n}, 0, \hat{A}^{I n c}(0, \widehat{D})\right)
$$


which is a contradiction.

\section{Proof of Proposition 4:}

Proof. Giving aid is optimal if the opposition uses violence without aid, meaning $\hat{A}^{O p p}(D=0)=$ $A_{L}^{O p p}$, and

$$
V^{I n c}\left(w, R ; D^{m i n}, 0, \hat{A}^{I n c}\left(A^{O p p}=0, D=D^{m i n}\right)\right)>V^{I n c}\left(w, R ; 0, A_{L}^{O p p}, \hat{A}^{I n c}\left(A^{O p p}=A_{L}^{O p p}, D=0\right)\right)
$$

or equivalently,

$$
\begin{gathered}
{\left[(1-\Theta)-\mathrm{\gamma}\left(0, \hat{A}^{I n c}\left(0, D^{\min }\right)\right)(1-2 \Theta)\right]\left[R-D^{\min }-w \hat{A}^{I n c}\left(0, D^{\min }\right)\right]>} \\
{\left[(1-\Theta)-\mathrm{\gamma}\left(0, \hat{A}^{I n c}\left(A_{L}^{O p p}, 0\right)\right)(1-2 \Theta)\right]\left[R-w \hat{A}^{I n c}\left(A_{L}^{O p p}, 0\right)\right]}
\end{gathered}
$$

The first term is the incumbent's utility giving $D^{\text {min }}$ aid and facing peace and the second is giving zero aid and facing violence.

To see that the incumbent should give aid for sufficiently small $D^{\min }$, first consider an incumbent who gives away a small amount of aid and induces peace, but does not change violence levels. With no aid, the incumbent's utility is

$$
\begin{gathered}
V^{I n c}\left(w, R ; 0, A_{L}^{O p p}, \hat{A}^{I n c}\left(A^{O p p}=A_{L}^{O p p}, D=0\right)\right)= \\
w+\left[(1-\Theta)-\gamma\left(A_{L}^{O p p}, \hat{A}^{I n c}\left(A^{O p p}=A_{L}^{O p p}, D=0\right)\right)(1-2 \Theta)\right]\left[R-w \hat{A}^{I n c}\left(A^{O p p}=A_{L}^{O p p}, D=0\right)\right] .
\end{gathered}
$$

With aid of $D^{\min }$ but not changing incumbent violence, the utility is

$$
\begin{gathered}
V^{I n c}\left(w, R ; D^{m i n}, 0, \hat{A}^{I n c}\left(A^{O p p}=A_{L}^{O p p}, D=0\right)\right)= \\
w+\left[(1-\Theta)-\gamma\left(0, \hat{A}^{I n c}\left(A^{O p p}=A_{L}^{O p p}, D=0\right)\right)(1-2 \Theta)\right]\left[R-D^{\text {min }}-w \hat{A}^{I n c}\left(A^{O p p}=A_{L}^{O p p}, D=0\right)\right] .
\end{gathered}
$$

We know that $\mathrm{\gamma}\left(0, \hat{A}^{I n c}\left(A^{O p p}=A_{L}^{O p p}, D=0\right)\right)<\mathrm{\gamma}\left(A_{L}^{O p p}, \hat{A}^{I n c}\left(A^{O p p}=A_{L}^{O p p}, D=0\right)\right)$, meaning that the chance of political turnover is smaller when the opposition uses peace rather than violence. We also know that $\left[R-w \hat{A}^{I n c}\left(A^{O p p}=A_{L}^{O p p}, D=0\right)\right]>0$, so for a sufficiently small $D^{\text {min }},[R-$ $\left.D^{m i n}-w \hat{A}^{I n c}\left(A^{O p p}=A_{L}^{O p p}, D=0\right)\right]>0$ as well. This means that even after giving away $D^{\text {min }}$, there is a prize with a positive value for whoever wins/holds power. For sufficiently small $D^{\min }$, 
the increased benefits arising from the increased chance of holding power outweighs the cost of reducing the prize pool slightly. This effect is at least as strong when the incumbent is allowed to optimize their violence in response to incumbent peace.

\section{Proof of Proposition 5:}

Proof. The inequalities in conditions 1, 3, and 4 are the same as (**) in Proposition 2 that give the threshold for $Z$ for when the opposition will use violence. Since only $Z_{M}$ is greater than the relevant threshold, the opposition will use violence only for $Z_{M}$. We note that the right-hand sides are algebraically equivalent for the three conditions, but they are evaluated at the different values for $Z$.

For example, $\hat{A}^{I n c}\left(A_{L}^{O p p}\right)$, which represents the optimal incumbent violence given a violent opposition, must be $A_{L}^{I n c}$ for $Z=Z_{M}$ and $A_{H}^{I n c}$ for $Z=Z_{H}$. We can pin down those values since Proposition 2 tells us that for all $Z \neq Z^{I n c}\left(A_{L}^{O p p} ; A_{L}^{I n c}, A_{H}^{I n c}\right), \hat{A}^{O p p}$ is non-decreasing in $Z$. $\hat{A}^{O p p}$ does increase as we increase $Z$ from $Z_{M}$ to $Z_{H}$, so we must have $Z_{M} \leq Z^{I n c}\left(A_{L}^{O p p} ; A_{L}^{I n c}, A_{H}^{I n c}\right)$ $<Z_{H}$. By Proposition 1, condition 2 is equivalent to the incumbent being peaceful in response to peace, and condition 5 is equivalent to the incumbent using violence in response to peace.

To sum up, the five conditions above are satisfied if and only if $Z_{L}$ leads to peace, $Z_{M}$ leads to civil conflict, and $Z_{H}$ leads to repression.

We can verify that some reasonable values of the parameters generate this result. Since poor countries generally do not give foreign aid, and we are modeling recipient countries, we will assume for simplicity that $\widehat{D}=0$. In general, $Z=(R+D) / w$, so with the assumption that the country is not giving aid, $Z_{L}=R_{L} / w, Z_{M}=R_{M} / w$, and $Z_{H}=R_{H} / w .{ }^{16}$ We consider an example where a low $R$ leaves the prize too low to justify violence, a medium $R$ causes both groups to use low violence because it is cheap, and a high $R$ means that an incumbent will use high violence in response to opposition violence, which deters the opposition and causes one-sided violence. The conditions on $Z_{L}$ are the most straightforward, and they can be treated separately. By Proposition

\footnotetext{
${ }^{16}$ Assuming aid $=0$ is consistent with the other assumptions made in the example. In the case of $R_{L}$ and $R_{H}$, we will see that the opposition is peaceful, meaning there is no need for aid. For $R_{M}$, we assume that violence is cheap and effective for both sides, meaning that the incumbent would need to give away a large amount of aid to guarantee peace, and it would not be worthwhile.
} 
2, sufficiently low $Z$ generates peace because the prize is too small to justify the cost of violence by either side.

We want to show that it is possible that $Z_{M}$ satisfies

1) $Z_{M} \in\left(Z^{I n c}\left(0 ; 0, A_{L}^{I n c}\right), Z^{I n c}\left(0 ; 0, A_{H}^{I n c}\right)\right)$,

2) $Z_{M}<Z^{I n c}\left(A_{L}^{O p p} ; A_{L}^{I n c}, A_{H}^{I n c}\right)$, and

3) $\hat{A}^{O p p}=A_{L}^{O p p}$

and $Z_{H}$ satisfies

4) $Z_{H}>Z^{I n c}\left(A_{L}^{O p p} ; A_{L}^{I n c}, A_{H}^{I n c}\right)$

5) $Z_{H} \in\left(Z^{I n c}\left(0 ; 0, A_{L}^{I n c}\right), Z^{I n c}\left(0 ; 0, A_{H}^{I n c}\right)\right)$

6) $\hat{A}^{O p p}=0$

Conditions 1 and 2 mean that for $Z_{M}$ the incumbent will use low violence against $A_{L}{ }^{O p p}$ or against peace, so $\hat{A}^{I n c}(0)=\hat{A}^{I n c}\left(A_{L}{ }^{o p p}\right)=A_{L}^{I n c}$. Condition 3 says for $Z_{M}$ the opposition will use violence. Conditions 4 and 5 say that the incumbent will use high violence against $A_{L}{ }^{O p p}$ and low violence against peace, and that the opposition will choose peace.

$Z^{I n c}\left(0 ; 0, A_{L}^{I n c}\right)$ is the threshold where the incumbent facing a peaceful opposition is indifferent between using low violence $\left(A_{L}{ }^{I n c}\right)$ and peace (higher $Z$ implies higher violence). $Z^{I n c}\left(0 ; 0, A_{L}^{I n c}\right)$ will be sufficiently low if $A_{L}^{I n c}$ is low and $\left(\mathrm{\gamma}(0,0)-\mathrm{\gamma}\left(0, A_{L}^{I n c}\right)\right)$ is not too low, meaning that low violence is very cheap and yields a significantly improved chance of holding power. $Z^{\text {Inc }}\left(0 ; 0, A_{H}{ }^{\text {Inc }}\right)$, the threshold between using high violence and low violence against peace, can be very high. Specifically, suppose that ${A_{H}}^{I n c}$ is high, and $\left(\mathrm{y}\left(0, A_{L}^{I n c}\right)-\mathrm{\gamma}\left(0, A_{H}^{I n c}\right)\right)$ is very low, meaning that high violence is very expensive and barely improves the incumbent's prospects, so $Z^{I n c}\left(0 ; 0, A_{H}^{I n c}\right)$ is very high. These values guarantee that the incumbent will use low violence against a peaceful opposition, satisfying condition 1 . The thresholds in condition 1 can be arbitrarily low and high, so it is simple to choose a $Z_{M}$ that satisfies condition 2 .

The third condition is satisfied when violence is sufficiently attractive for the opposition. This is condition 2 from proposition 5, but now we have specified the incumbent's optimal levels of violence, so we can substitute those in: 


$$
\begin{gathered}
Z_{L}>\left(\left(A_{L}^{O p p} / 2\right)+\left[\Theta+\gamma\left(A_{L}^{O p p}, A_{L}^{I n c}\right)(1-2 \Theta)\right] A_{L}^{I n c}-\right. \\
\left.\left[\Theta+\gamma\left(0, A_{L}^{I n c}\right)(1-2 \Theta)\right] A_{L}^{I n c}\right) /\left((1-2 \Theta)\left(\gamma\left(A_{L}^{O p p}, A_{L}^{I n c}\right)-\gamma\left(0, A_{L}^{I n c}\right)\right)\right)
\end{gathered}
$$

This condition is met when $A_{L}^{O p p}$ is sufficiently low and $\left(\mathrm{\gamma}\left(A_{L}^{O p p}, A_{L}^{I n c}\right)-\mathrm{\gamma}\left(0, A_{L}{ }^{I n c}\right)\right)$ is high, meaning that opposition violence is inexpensive but effective. Together, these give us conditions under which the first three assumptions are satisfied.

The fourth condition is met by fixing some sufficiently high $Z_{M}$. Condition 5 will not be violated as long as $Z^{I n c}\left(0 ; 0, A_{H}^{I n c}\right)$ is high enough. It can be arbitrarily large as long as ( $\mathrm{\gamma}(0$, $\left.\left.A_{L}^{I n c}\right)-\mathrm{\gamma}\left(0, A_{H}^{I n c}\right)\right)$ is close to zero. Once the first five conditions are met, the sixth would plausibly be met as well. The opposition has the choice between peace, which is met with low violence, and violence, which is met with high violence. The opposition's chance of gaining power may not even be improved by using violence, and they use up their own resources and cause the incumbent to waste more state resources with a larger army. Thus, it is possible to observe the pattern that we are interested in: a country is peaceful before receiving any aid, then repressive when receiving generous aid, and engulfed in civil conflict when that aid is reduced. 


\section{Appendix B: Infinite-Period Model with Capital Investment}

In the body of the paper, we assumed that the groups only care about the present period, which meant that a one-period (infinitely repeating) model sufficed. In this section we adopt a fuller infinite-period model, where agents care about every period. This can be interpreted either as an infinitely-lived agent or as one who feels altruistic towards future generations of the group; in either case, the future is discounted by a factor of $\beta<1$. In addition, we introduce the capability to invest in capital, which increases the level of resources available in the next period. This model shows a pernicious effect of violence that cannot be captured in the one-period version: the possibility of civil conflict forces the incumbent to make an inefficiently low level of investment.

The timing of the model is slightly more complex:

1. Capital $K_{t}$ was determined last period.

2. Exogenous resources $R_{t}$ is $R^{H}$ with probability $\alpha, R^{L}$ with probability $1-\alpha$.

3. Aid $D_{t} \geq 0$ chosen by the incumbent.

4. Opposition violence $A_{t}^{O p p} \in\left\{0, A_{L}^{O p p}\right\}$ chosen.

5. Incumbent violence $A_{t}^{I n c} \in\left\{0, A_{L}^{I n c}, A_{H}^{I n c}\right\}$ chosen.

6. Conflict function $\mathrm{y}$ resolved.

7. Define $Z_{t}=\mathrm{F}\left(K_{t}\right)+R_{t}-D_{t}$. State resources are $Z_{t}-A_{t}^{I n c}$. They can be divided between $K_{t+1}$ and consumption (wage is normalized to 1 ).

8. Distribute consumption: incoming incumbent gets $(1-\theta)\left(Z_{t}-A_{t}^{\text {Inc }}-K_{t+1}\right)$, incoming opposition gets $\theta\left(Z_{t}-A_{t}^{\text {Inc }}-K_{t+1}\right)$. They also get to consume their wages: outgoing incumbent gets 1 , outgoing opposition gets $1-A_{t}^{O p p}$.

We make standard assumptions about the functional form of the production function. One, $\mathrm{F}(K)$ is increasing over $\left[0, K^{\max }\right]$. Two, $\mathrm{F}^{\prime}(K)$ is decreasing everywhere. As before, utility is linear.

Equilibrium: We now show that this relatively simple extension supports a strategy in which the incumbent spends on foreign aid in lieu of capital investment so as to reduce the incentives of the opposition to mount an insurgency.

There is a wide range of Nash equilibria in the infinite game. We are looking to show that a particular type of Nash equilibrium, where both groups play the same strategy $\boldsymbol{\sigma}$, can be 
supported for some values of parameters. In this equilibrium there is always peace and the incumbent gives away aid only in high-resource periods. Defining $\boldsymbol{\sigma}$ :

1. $K^{*}$ and $Z^{*}$ are fixed, and the same for both groups.

2. If $\mathrm{F}\left(K_{t}\right)+R_{t}>Z^{*}$, incumbent gives away aid $D_{t}=\mathrm{F}\left(K_{t}\right)+R_{t}-Z^{*}$, so $Z_{t}=Z^{*}$.

3. Opposition uses violence if and only if $Z_{t}>Z^{*}$.

4. The incumbent is peaceful towards a peaceful opposition (i.e., no repression.) If opposition attacks, incumbent uses $A_{L}^{I n c}$.

5. Incumbent saves $K^{*}$, or saves everything if it does not have $K^{*}$, and distributes the rest for current consumption.

Proposition: For some values of parameters, it is a Nash equilibrium for both groups to play $\boldsymbol{\sigma}$, assuming initial capital is $K_{0}=K^{*}$.

Proof. We show how if one side is following $\sigma$, the other's best response will be to do the same. We first fix any $Z^{*}>0$ and define $K^{*}$ by $\mathrm{F}\left(K^{*}\right)=Z^{*}+R_{L}$. Assume the current opposition is playing $\boldsymbol{\sigma}$ with fixed $K^{*}, Z^{*}$. We want to show that for some values of parameters, the best response for the current incumbent is to also play $\boldsymbol{\sigma}$. Note that an incumbent who saves $K^{*}$, receives a low resource draw, and gives no aid in the next period will experience a peaceful opposition, but any larger investment or a high resource draw will cause the opposition to attack (in the absence of aid). There are several possible deviations from $\boldsymbol{\sigma}$ for the incumbent.

(i) Save more: $K_{t+1}>K^{*}$, and donate aid to ensure peace next period.

(ii) Save more: $K_{t+1}>K^{*}$, and donate aid during low-resource periods to ensure peace, but fight during high-resource periods.

(iii) Save more: $K_{t+1}>K^{*}$, and fight regardless of the draw.

(iv) Save the same: $K_{t+1}=K^{*}$, but fight during high draws.

(v) Save less: $K_{t+1}<K^{*}$.

(vi) Use repression against a peaceful opposition.

We also need to verify that if the current incumbent is playing $\boldsymbol{\sigma}$, then playing $\boldsymbol{\sigma}$ is a best response for the opposition. There is only one possible deviation from $\boldsymbol{\sigma}$ for the opposition:

(vii) Attack for some different values of $Z_{t}$.

Consider deviation (i). A deviation would occur in step 7 of the timing, when the incumbent is dividing the state resources $Z_{t}-A_{t}^{I n c}$ between $K_{t+1}$ and consumption. The incumbent is planning on peace regardless of the draw of $R_{t+1}$, so there is no reason to save more 
than $K^{*}$, because any excess savings will have to be given away as aid to deter violence next period.

To rule out deviations (ii), (iii), and (iv), we will need assumptions on the parameters. Fighting carries a fixed cost for one period, but the opportunity to save more than $K^{*}$ generates extra resources that may compensate for that. We will assume that civil conflict decreases an incumbent's chance of holding power relative to peace, which translates to a decrease in the continuation value for future periods. In symbols, $y_{p}<\gamma_{c}$, where $y_{p}$ is the chance of power changing hands during peace and $\gamma_{c}$ is the chance of power changing hands during civil conflict. If $K^{\max }+R^{H}$ is sufficiently close to $K^{*}+R^{L}$ then the benefits of increasing investment will always be swamped by the fixed cost of fighting, and the decreased continuation value will only compound the negatives of investing over $K^{*}$. If fighting is unappealing for high resource draws, then it must be for low draws as well.

Saving less than $K^{*}$, as in (v), is attractive only if the returns on investment are sufficiently low. There is no reason to give away any less than $K^{*}$ if $(1-\alpha) \beta \mathrm{F}^{\prime}\left(K^{*}\right)\left[\left(1-\mathrm{\gamma}_{\mathrm{p}}\right)(1-\right.$ $\left.\theta)+\gamma_{\mathrm{p}} \theta\right] \geq 1-\theta$.The left-hand side represents the benefit from increasing savings from $\left(K^{*}-\varepsilon\right)$ to $K^{*}$ and consuming the proceeds in the next period if the resource draw is $R^{L}$. The $1-\alpha$ term captures the fact that there may be no benefit gained if $R_{t+1}=R^{H}$, and $\beta$ is the usual time discounting. The term in brackets is the amount of the extra investment that the current incumbent will get to consume as the incumbent or opposition next period, weighted by the likelihood that it holds power. The right side is the immediate benefit to the incumbent from distributing the extra resources for consumption instead. If $\mathrm{F}^{\prime}\left(K^{*}\right)$ is high enough, the inequality holds.

Repression (vi) will be profitable if the fixed cost of violence is outweighed by the increased expected payoff this period plus the increased expected continuation value for future periods. Both benefits are driven by the improved likelihood of holding power, so when the gain is sufficiently small, repression is not profitable for any feasible $K$.

Finally, we need to find conditions under which there is no profitable deviation for group the opposition, assuming the incumbent plays $\boldsymbol{\sigma}$ (vii). For simplicity, we are assuming that $\boldsymbol{\sigma}$ dictates using $A_{L}^{I n c}$ rather than $A_{H}^{I n c}$ in response to violence, but this assumption could be changed without any substantive modifications to the argument. Define $\mathrm{U}^{\mathrm{Inc}}(K ; \boldsymbol{\sigma})$ as the maximum achievable infinite-period discounted value of starting a period as the incumbent with 
capital level $K \in\left[0, K^{m a x}\right]$, given that the other group is playing strategy $\boldsymbol{\sigma}$. $\mathrm{U}^{\mathrm{Opp}}(K ; \boldsymbol{\sigma})$ is defined analogously. For any $K \in\left[0, K^{\max }\right]$, assuming the current incumbent will play $\boldsymbol{\sigma}$, the opposition will start a civil conflict if:

$$
\begin{gathered}
\left(1-\mathrm{\gamma c}_{\mathrm{c}}\right)\left[\theta\left(Z-A_{L}^{\mathrm{Inc}}-K^{*}\right)-A_{L}^{O p p}+\beta \mathrm{U}^{\mathrm{Opp}}\left(K^{*} ; \boldsymbol{\sigma}\right)\right]+\mathrm{\gamma c}_{\mathrm{c}}\left[(1-\theta)\left(Z-A_{L}^{\text {Inc }}-K^{*}\right)-A_{L}^{O p p}+\beta\right. \\
\left.\mathrm{U}^{\mathrm{Inc}}\left(K^{*} ; \boldsymbol{\sigma}\right)\right]>\left(1-\mathrm{\gamma p}_{\mathrm{p}}\right)\left[\theta\left(Z-K^{*}\right)+\beta \mathrm{U}^{\mathrm{Opp}}\left(K^{*} ; \boldsymbol{\sigma}\right)\right]+\mathrm{\gamma p}_{\mathrm{p}}\left[(1-\theta)\left(Z-K^{*}\right)+\beta \mathrm{U}^{\mathrm{Inc}}\left(K^{*} ; \boldsymbol{\sigma}\right)\right]
\end{gathered}
$$

The first term on the left side represents the total value (current payoff plus continuation value) under unsuccessful civil conflict, meaning power does not change hands. The second term on the left side is the corresponding value when power does change hands, and the right hand side is the analog under peace. Note that we assume for simplicity that the incumbent will have enough resources left after financing an army to be able to afford $K^{*}$ of investment.

In order to support the equilibrium, we want the opposition to choose violence if and only if $Z \geq Z^{*}$. This is equivalent to $Z^{*}$ solving (*) with equality:

$$
\begin{gathered}
\beta\left(\mathrm{\gamma}_{\mathrm{c}}-\mathrm{\gamma}_{\mathrm{p}}\right)\left(\mathrm{U}^{\mathrm{Inc}}\left(K^{*} ; \boldsymbol{\sigma}\right)-\mathrm{U}^{\mathrm{Opp}}\left(K^{*} ; \boldsymbol{\sigma}\right)\right)= \\
\left(Z^{*}-K^{*}\right)\left[\left(1-\mathrm{\gamma}_{\mathrm{p}}\right) \theta+\mathrm{\gamma}_{\mathrm{p}}(1-\theta)\right]-\left[\left(Z-A_{L}^{I n c}-K^{*}\right)\left(\left(1-\mathrm{\gamma}_{\mathrm{c}}\right) \theta+\mathrm{\gamma}_{\mathrm{c}}(1-\theta)\right)-A_{L}{ }^{O p p}\right]
\end{gathered}
$$

The left hand side represents the increase in continuation value from using violence in the current period, while the right side represents the net gain or loss in the current period. For sufficiently low $A_{L}^{I n c}, A_{L}^{O p p}$, and $\gamma_{\mathrm{p}}$, violence is attractive, meaning the left side of the equation is larger.

Holding $\gamma_{c}$ fixed and increasing $\gamma_{p}$ will decrease the appeal of violence in several ways: the expected current-period payoff from peace is improved, raising the right hand side; $\left(\mathrm{\gamma}_{\mathrm{c}}-\mathrm{\gamma}_{\mathrm{p}}\right)$ shrinks, as does $\left(\mathrm{U}^{\mathrm{Inc}}\left(K^{*} ; \boldsymbol{\sigma}\right)-\mathrm{U}^{\mathrm{Opp}}\left(K^{*} ; \boldsymbol{\sigma}\right)\right)$, meaning that attacking gives a smaller increase in the chance to gain power; and the difference in continuation gets smaller as well. By continuity, there is some $\mathrm{y}_{\mathrm{p}}$ where the equality holds as desired. $\square$

This equilibrium represents an inefficiently low level of savings. For comparison, consider an identical model with the same parameters in which violence is not allowed. Now both groups playing $\boldsymbol{\sigma}$ is not an equilibrium. If the current opposition plays $\boldsymbol{\sigma}$, the incumbent can 
profitably deviate by investing more and enjoying increased consumption in the next period, regardless of who in is power. This can be seen because we have assumed $(1-\alpha) \beta \mathrm{F}^{\prime}\left(K^{*}\right)[(1-$ $\left.\left.\gamma_{p}\right)(1-\theta)+\gamma_{p} \theta\right] \geq 1-\theta$. The $(1-\alpha)$ term represents the fact that investing more in the current period gives no benefit in the next period if there is a high resource draw because the surplus will have to be donated away to ensure peace. When peace is not allowed, resources that are saved are guaranteed to be available, so now the incumbent wants to save more than $K^{*}$. In symbols, $\beta \mathrm{F}^{\prime}\left(K^{*}\right)\left[\left(1-\gamma_{\mathrm{p}}\right)(1-\theta)+\mathrm{\gamma}_{\mathrm{p}} \theta\right]>1-\theta$. The discounted payoff from saving, $\beta \mathrm{F}^{\prime}\left(K^{*}\right)$, multiplied by the expected share that the current incumbent will receive, $\left[\left(1-\gamma_{p}\right)(1-\theta)+{ }_{p} \theta\right]$, is larger than the incumbent's share of consumption, $1-\theta$.

The possibility that the other group will attack causes the incumbent group to hold the discounted present value of having power below a certain threshold. This is consistent with the observed low levels of investment in violence-plagued countries around the world (Besley and Persson 2011b). 


\section{Appendix C: Additional Results}

Table C1: Difference-in-difference estimates of foreign aid (\% GDP)

\begin{tabular}{lcccccc} 
& \multicolumn{3}{c}{ Aid (\% GDP) } & & \\
& & & & & \\
& Non-Muslim & Muslim & Difference & Std Error & Difference-in-difference & Std Error \\
\hline Before: $1960-1972$ & 4.12 & 4.57 & 0.45 & {$[1.024]$} & & \\
During: 1973-1985 & 6.57 & 12.82 & 6.24 & {$[3.215]^{*}$} & 5.79 & {$[2.642]^{* *}$} \\
After: 1986-1999 & 10.81 & 11.76 & 0.96 & {$[2.344]$} & -5.29 & {$[2.288]^{* *}$} \\
Post 2000: $2000-2008$ & 8.81 & 9.59 & 0.78 & {$[2.283]$} & -0.17 & {$[1.998]$}
\end{tabular}

Notes: Standard errors are clustered by country reported in brackets. $*=$ significant at $10 \%$; $* *=$ significant at $5 \%: * * *=$ significant at $1 \%$. 


\section{Appendix D: Data}

Table D1: Sample of countries

\begin{tabular}{|c|c|c|c|c|c|c|c|}
\hline Country & Muslim & Foreign aid & POLITY & Country & Muslim & Foreign aid & POLITY \\
\hline Afghanistan & $\mathrm{X}$ & 11.66 & -6.35 & Latvia & & 1.11 & 8.00 \\
\hline Albania & $X$ & 10.07 & -3.14 & Lebanon & $X$ & 2.51 & 2.29 \\
\hline Armenia & & 8.53 & 4.16 & Lesotho & & 16.91 & -0.34 \\
\hline Bangladesh & $X$ & 4.57 & 0.34 & Liberia & & 24.93 & -3.02 \\
\hline Belarus & & 0.54 & -3.68 & Lithuania & & 1.13 & 10.00 \\
\hline Benin & & 8.20 & -0.92 & Macedonia, FYR & & 4.03 & 7.26 \\
\hline Bhutan & & 15.54 & -9.24 & Madagascar & & 8.06 & 0.30 \\
\hline Bolivia & & 5.90 & 2.58 & Malawi & & 17.61 & -3.87 \\
\hline Bosnia \& Herzegovina & & 15.94 & 0.00 & Mali & $\mathrm{X}$ & 15.03 & -1.92 \\
\hline Botswana & & 8.32 & 6.82 & Mauritania & $\mathrm{X}$ & 16.81 & -6.12 \\
\hline Bulgaria & & 1.84 & -0.82 & Mauritius & & 1.91 & 9.67 \\
\hline Burkina Faso & & 10.47 & -4.16 & Moldova & & 5.08 & 7.26 \\
\hline Burundi & & 17.46 & -3.52 & Mongolia & & 9.80 & -0.60 \\
\hline Cambodia & & 9.00 & -2.80 & Morocco & $\mathrm{X}$ & 2.68 & -7.22 \\
\hline Cent. African Rep. & & 10.70 & -3.72 & Mozambique & & 27.17 & -1.74 \\
\hline Chad & & 9.27 & -5.08 & Namibia & & 4.11 & 6.00 \\
\hline Chile & & 0.52 & 3.10 & Nepal & & 6.32 & -2.92 \\
\hline Comoros & $X$ & 20.03 & 0.26 & Nicaragua & & 11.07 & -0.40 \\
\hline Congo, Dem. Rep. & & 7.39 & -4.44 & Niger & $\mathrm{X}$ & 10.81 & -3.00 \\
\hline Costa Rica & & 1.63 & 10.00 & Pakistan & $\mathrm{X}$ & 3.72 & 0.34 \\
\hline Cote d'Ivoire & & 3.57 & -6.42 & Panama & & 1.28 & 1.56 \\
\hline Croatia & & 0.36 & 2.84 & Paraguay & & 1.75 & -2.02 \\
\hline Czech Republic & & 0.38 & 9.53 & Philippines & & 1.23 & 2.44 \\
\hline Djibouti & $X$ & 18.91 & -4.36 & Poland & & 1.23 & -0.34 \\
\hline Dominican Rep. & & 1.66 & 3.62 & Rwanda & & 16.71 & -5.65 \\
\hline El Salvador & & 3.23 & 2.94 & Senegal & $X$ & 8.27 & -1.10 \\
\hline Eritrea & $X$ & 24.08 & -6.53 & Sierra Leone & & 12.65 & -1.69 \\
\hline Estonia & & 1.22 & 7.63 & Slovak Republic & & 0.46 & 8.65 \\
\hline Ethiopia & & 9.86 & -4.58 & Somalia & $X$ & 27.81 & -1.82 \\
\hline Fiji & & 2.77 & 5.30 & South Africa & & 0.32 & 5.76 \\
\hline Gambia, The & & 17.60 & 3.07 & Sri Lanka & & 4.46 & 6.08 \\
\hline Georgia & & 5.92 & 5.26 & Sudan & $\mathrm{X}$ & 3.90 & -4.12 \\
\hline Ghana & & 6.18 & -2.02 & Swaziland & & 4.80 & -8.40 \\
\hline Guatemala & & 1.35 & 1.50 & Tajikistan & $\mathrm{X}$ & 8.89 & -3.32 \\
\hline Guinea & $\mathrm{X}$ & 7.66 & -6.00 & Tanzania & & 16.62 & -4.30 \\
\hline Guinea-Bissau & & 39.54 & -2.17 & Togo & & 8.27 & -5.24 \\
\hline Guyana & & 11.99 & 0.86 & Turkey & $X$ & 0.63 & 6.72 \\
\hline Haiti & & 10.58 & -4.60 & Uganda & & 8.28 & -3.00 \\
\hline Honduras & & 5.53 & 3.22 & Ukraine & & 0.79 & 6.47 \\
\hline Hungary & & 0.47 & 0.12 & Uruguay & & 0.38 & 4.90 \\
\hline Jamaica & & 2.29 & 9.65 & Zambia & & 12.30 & -1.72 \\
\hline Jordan & $\mathrm{X}$ & 12.46 & -6.44 & Zimbabwe & & 2.83 & -1.33 \\
\hline Kenya & & 5.86 & -2.64 & & & & \\
\hline Kyrgyz Republic & $\mathrm{X}$ & 11.48 & -1.47 & & & & \\
\hline Lao PDR & & 12.95 & -5.06 & & & & \\
\hline
\end{tabular}

Notes: Sample of poor, non-oil producing countries. Foreign aid is a share of GDP. 
Table D2: Political and economic conditions in poor, non-oil producing Muslim and nonMuslim countries in 1972

\begin{tabular}{lcccc} 
& Non-Muslim & Muslim & Difference & P-value \\
\hline GDP per capita (2005 US\$) & 1060.75 & 585.11 & 475.64 & $\mathbf{0 . 2 1}$ \\
Aid (\% GDP) & 4.70 & 4.83 & -0.13 & $\mathbf{0 . 9 3}$ \\
POLITY & -3.57 & -4.67 & 1.10 & $\mathbf{0 . 5 3}$ \\
Executive constraints & 2.75 & 2.57 & 0.18 & $\mathbf{0 . 7 8}$ \\
Civil war (> 25 battle deaths) & 0.15 & 0.07 & 0.08 & $\mathbf{0 . 4 0}$
\end{tabular}




\section{Appendix E: Discounting Alternate Explanations}

A potential concern with the "natural experiment" findings, that an exogenous increase in aid leads to more conflict, is that factors correlated with oil prices that are independent of foreign aid flows may be driving the differential effects in conflict propensity. In this Appendix, we investigate the main potential alternative explanations.

\section{Remittances}

At the same time Gulf oil producers were disbursing aid, they also "imported" labor from non-oil producing Muslim countries. These workers in turn remitted much of this income back to their home. And as with aid, remittances received in non-oil producing Muslim countries is also correlated with the price of oil (Ahmed 2012). Unlike aid, though, remittances are received by households and not by the government, so the link between remittances and conflict is less direct and is likely to worse in the opposite direction as aid. That is, higher remittance income during the period of high oil prices should empower individuals and fuel conflict—which corresponds to how opposition investment in violence is modeled in this paper, through their income. Yet, this is not observed in Muslim countries as the likelihood of civil war was much lower in the high oil price period compared to the subsequent period of lower oil prices. Moreover, controlling for remittances in the difference-in-difference estimates does not affect our core findings, reported in Table D1, column 1. This allays concerns that excluding remittance inflows constitutes omitted variable bias.

Each row reports the relevant difference-in-difference coefficient. For instance, the estimate in the first row ("During") reports the difference-in-difference in the likelihood of twosided conflict between Muslim and non-Muslim non-oil producers across the pre-oil boom period (1960-1972) and the oil boom period (“during”, 1973-1985). The difference-in-difference estimates are slightly less robust than those reported in the main text due to the smaller sample size (since remittances data was less prevalent in the 1970s).

\section{Table E1: Difference-in-Difference Coefficient Estimates}




\begin{tabular}{lccccc} 
Dependent variable: & \multicolumn{5}{c}{ Incidence of civil war (at least 1000 battle deaths per year) } \\
\hline \hline & $(1)$ & $(2)$ & $(3)$ & $(4)$ & $(5)$ \\
During: 1973-1985 & -0.04 & -0.07 & -0.07 & -0.07 & -0.06 \\
& {$[0.036]$} & {$[0.047]$} & {$[0.047]$} & {$[0.144]$} & {$[0.043]$} \\
After: 1986-1999 & $\mathbf{0 . 0 9}$ & $\mathbf{0 . 1 2}$ & $\mathbf{0 . 1 2}$ & $\mathbf{0 . 1 3}$ & $\mathbf{0 . 1 1}$ \\
& {$[\mathbf{0 . 0 5 8}]^{*}$} & {$[\mathbf{0 . 0 5 9}]^{* *}$} & {$[\mathbf{0 . 0 6 0}]^{* *}$} & {$[\mathbf{0 . 0 6 2}]^{* *}$} & {$[\mathbf{0 . 0 5 8}]^{*}$} \\
Post 2000: 2000-2008 & -0.04 & -0.09 & -0.09 & -0.10 & -0.09 \\
& {$[0.047]$} & {$[0.052]^{*}$} & {$[0.052]^{*}$} & {$[0.055]^{*}$} & {$[0.049]^{*}$} \\
\hline Additional controls & Remittances (\% GDP) & \multicolumn{3}{c}{ Assassinations } \\
Excluded countries & & Lebanon & Morrocco & Lebanon & \\
& & & & Morrocco &
\end{tabular}

Notes: Standard errors are clustered by country reported in brackets.

$\wedge=$ significant at $15 \% ; *=$ significant at $10 \% ; * *=$ significant at $5 \%$ : *** = significant at $1 \%$.

\section{Exporting Islamic Extremism}

Perhaps the most troublesome concern is that oil prices allowed Gulf oil producers to affect the internal politics of non-oil producing Muslim countries, independent of the foreign aid channel. After all, when the price of oil was high, OPEC countries were not only giving money away, they were exporting politics. In particular, there were three major players whose influence benefited from the high oil prices: Ayatollah Khomeini in Iran, Moammar Qadhafi in Libya, and the religious hardliners in Saudi Arabia. Khomeini tried to export the Iranian revolution, Qaddafi funded insurgencies of all sorts, and the Saudis pushed Wahhabi beliefs on Muslims around the world. These policies had the potential to lead to instability down the road in the poor Muslim countries who received the foreign aid windfalls. The balance of evidence, however, suggests that none of these three stories biases the findings of the paper.

There are two specific dangers that any of these stories can pose to the analysis thus far. One, the political interventions on the part of Iran, Libya, or Saudi Arabia could lead to the data being coded in a way that would falsely indicate a rise in civil war (i.e., non-internationalized internal conflict) after the fall of oil prices. Specifically, we are worried that these countries may have been intervening in domestic conflicts at the same time that the poor Muslim countries were receiving aid windfalls. ${ }^{17}$ Two, the political interventions of these states during the high oil price years could have planted the seeds for future internal conflict in a channel unrelated to foreign

\footnotetext{
${ }^{17}$ If Libya, for example, were intervening in an internal war in Niger while the price of oil was high, the war in Niger could have been coded as internationalized at the same time that Niger received a foreign aid bonus from the Gulf states. Then, when the price of oil fell, Libya might have run out of money and stopped intervening - resulting in the conflict being coded as "non-internationalized" just as the foreign aid fell. This would generate the same results that the paper has put forward thus far: a rise in foreign aid coinciding with the fall in non-internationalized internal conflict, then the fall in foreign aid coinciding with a rise in non-internationalized internal conflict.
} 
aid. Most saliently, the export of radical Islam no doubt gained steam during the 1970s and early 1980s. Perhaps the ideas promulgated during the high oil price years needed time to germinate before they would realize themselves in domestic instability after the oil price had fallen.

The first danger is the easiest to address. As it turns out, there were only two non-oilproducing Muslim countries that, according to ACD, experienced internal conflict over the period 1973-85 which entailed interventions by other Muslim countries for some duration of the conflict. $^{18}$ They were Lebanon (1982-1986) and Morocco (1975-1989). In 1983 and 1984 Lebanon's conflict is not coded as internal because of intervention on the part of Israel and Syria. It seems reasonable to code this as an internationalized internal conflict: the typical analysis of this conflict is that Lebanon served as the fighting grounds for the war between Israel and the Palestinian Liberation Organization as well as Syria (e.g. Murphy, 2002, 49-57).

In the ACD, Morocco experienced civil war from 1975-1989. For the first 5 years, this conflict was coded as internationalized (only in 1976 by ACD though) because of Mauritanian involvement in putting down the rebel group Polisario's secession aims for Western Sahara. After a coup in Mauritania, the new government signed a cease-fire with Polisario and granted them control over disputed territory that lied in Mauritania. From 1980-89 the conflict between the Moroccan government and the rebels, ACD codes the conflict as internal.

Of course, the goal is not to evaluate every data point in the ACD conflict series. To make sure the results are not driven by these two conflicts, we repeat our difference-in-difference analysis dropping Lebanon, Morocco, or both. We report the difference-in-difference estimates in table $\mathrm{C} 1$, columns 2-4. As it turns out, the double differences remain statistically significant, indicating that Muslim countries' involvement in the internal conflicts of other Muslim countries during the period of high oil prices can not explain the subsequent rise in internal conflict.

The second danger, that Islamic political influences during the period 1973-1985 planted the seeds for future internal conflict, is much harder to discount. Evidence, however, suggests that the surge in Islamism and the increasing power and political activism of traditionalist religious groups is an outcome rather than a cause of the political economy of the state that is fed by foreign aid.

\footnotetext{
${ }^{18}$ Certainly, this understates Libyan involvement. Geoff Simons (1996, 281) cites an Israeli intelligence report that in 1986 Qadhafi was supporting some "fifty terror organizations and subversion groups, in addition to more than forty radical governments in Africa, Asia, Europe and America." If all these interventions had been coded as internationalized, however, the results could be biased towards seeing all domestic conflict as internationalized.
} 
For example, during 1979 in Iran, Ayatollah Khomeini led a successful revolution that seized power from the American-backed shah whose regime had ignored crucial segments of the populace. The Iranian revolution spawned what Gilles Kepel calls a "ripple effect":

Regimes in Muslim countries viewed the shah's fate as an object lesson, and many of them became ostentatiously religious, in the hope of avoiding what had befallen the Persian monarch, who had never bothered to hide his contempt for the "men in black." Governments sought to head off social movements that, by annexing the vocabulary of Islam, threatened to unite everyone with an axe to grind and bring down the established power. The ulemas, having been steadily harassed during the nationalist period, now found themselves fawned upon by princes eager for the Islamic legitimacy their blessing could confer. In return, the clerics demanded greater control over culture and morals. $(2002,118)$

In other words, the Islamic Revolution in Iran had an indirect, positive effect on Islamism in other Muslim countries (and potentially non-Muslim countries where the successes in Iran could be adapted). Governments, feeling distant from and threatened by their constituencies that they were otherwise repressing or buying off with the foreign aid rents, made concessions to the segment of the populace that was most threatening. In this case, that segment was religious, but there are other examples within Muslim countries during the same time period where the segment was not religiously defined, as in Somalia. The foreign aid windfall would certainly have been used to help make these concessions, in the construction of mosques and the funding of Islamic groups within the nation. In our model, this would imply a temporary increase in $\sigma$.

With respect to the spread of Wahhabism from Saudi Arabia, Kepel acknowledges the shift in power in the Muslim world to the Gulf states upon the beginning of the oil embargo. Yet he is skeptical that this wealth was able to influence any fundamental change in poor Muslim countries:

[Saudi Arabia's] immense financial generosity had won it a following that was more venal than sincere, and the Wahhabization it wished to implement had tended to fluctuate with the price of a barrel of oil. (73)

An example of the failure of Saudi's export of Islam can be seen in the far west of Africa. In Senegal, stable with the exception of the separatist Casamance region in the south, the influence of fundamentalist Islam was easily controlled: 
When Islamism began to appear in Senegal in the late 1970s among students who were inspired by the Iranian revolution or educated in Arab universities in the Middle East, it immediately collided with the power of the marabouts. Radical Islamism was allowed a hearing only so long as it did no harm to the marabouts' interests; as soon as the movement showed signs of doing so, the religious leaders squashed it. (Kepel, 2002, 50)

Likewise, in Morocco - where King Hassan II had claimed to be a direct descendent of the prophet Mohammed - the reach of Wahhabism was limited. The Islamist movement encountered "difficulty in contriving a political rupture with the state without calling into question the monarch's sacredness, a taboo to which the mass of the populace was resolutely opposed" (Kepel, 2002, 55).

Even if the Islam exported by Saudi Arabia was not inherently successful in infiltrating the dominant practice of Islam in recipient countries, it may have encouraged radical groups at the fringe of society. This is equivalent to saying that the level of extremism increased as a result of Saudi influence. If such a story is correct, this implies that the analysis in the paper thus far ignores an important factor: religious extremism. In order to measure the effect of aid on instability independent of extremism, one must control for the latter.

To check whether this indeed might be the case, we use assassinations as a proxy for extremism to test whether extremism may have been produced by the foreign aid windfalls. We repeat our empirical analysis controlling for the number of assassinations each year (available from Banks 2010), reported in table C1 column 5. Controlling for the level of extremism does not appreciably change the pattern between the foreign aid windfall and high intensity, two-sided civil war. The difference-in-difference estimates remain largely unchanged.

In sum, the evidence supports the notion that movements in Islamism among poor Muslim nations - though coinciding with oil price movements and Saudi foreign policy — were a fundamental part of those nations' internal politics and the consequences of elites' otherwise repressing the population. The robustness checks also suggest that the specificities of coding the data cannot alone explain the pattern in conflict, nor can the omission of religious extremism that might have been independently generated by the foreign policies of Iran and Saudi Arabia in particular. 


\section{Appendix F: Does Western Development Aid Favor Less Repressive Governments?}

\section{Table F1: Predicted Aid Receipts from DAC Donors Controlling for Executive Constraints}

Dependent variable: $\quad$ Total bilateral aid from DAC donors (\% GDP)

By decade

\begin{tabular}{lcccccc} 
& Entire & $\mathbf{1 9 6 0}$ & $\mathbf{1 9 7 0}$ & $\mathbf{1 9 8 0}$ & $\mathbf{1 9 9 0}$ & $\mathbf{2 0 0 0}$ \\
\hline Log GDP per capita (2000 US\$) & -3.442 & -1.742 & -2.239 & -3.313 & -3.722 & -4.248 \\
& {$[0.478]^{* * *}$} & {$[0.613]^{* * *}$} & {$[0.429]^{* * *}$} & {$[0.804]^{* * *}$} & {$[0.672]^{* * *}$} & {$[0.631]^{* * *}$} \\
Executive constraints & -0.375 & -0.209 & 0.038 & -0.393 & 0.169 & -0.74 \\
& {$[0.148]^{* *}$} & {$[0.334]$} & {$[0.159]$} & {$[0.275]$} & {$[0.316]$} & {$[0.334]^{* *}$} \\
Constant & 29.117 & 15.612 & 18.072 & 28.835 & 31.055 & 35.561 \\
& {$[3.758]^{* * *}$} & {$[5.224]^{* * *}$} & {$[3.333]^{* * *}$} & {$[6.458]^{* * *}$} & {$[5.293]^{* * *}$} & {$[5.137]^{* * *}$} \\
\hline R-squared & 0.24 & 0.11 & 0.26 & 0.21 & 0.28 & 0.36 \\
No. of observations & 2801 & 338 & 470 & 554 & 750 & 689 \\
\hline
\end{tabular}

Notes: Standard errors, clustered by country reported in brackets.

Executive constraints is a 7-point index (1 through 7) where higher values correspond to a less constrained executive (i.e., more repressive).

$*=$ significant at $10 \% ; * *=$ significant at $5 \%: * * *=$ significant at $1 \%$.

Table F2: Predicted Aid Receipts from DAC Donors Controlling for Political Rights

Dependent variable: $\quad$ Total bilateral aid from DAC donors (\% GDP)

By decade

\begin{tabular}{lcccccc} 
& Entire & $\mathbf{1 9 6 0}$ & $\mathbf{1 9 7 0}$ & $\mathbf{1 9 8 0}$ & $\mathbf{1 9 9 0}$ & $\mathbf{2 0 0 0}$ \\
\hline Log GDP per capita (2000 US\$) & -3.916 & -- & -2.413 & -3.275 & -3.99 & -4.516 \\
& {$[0.570]^{* * *}$} & -- & {$[0.444]^{* * *}$} & {$[0.776]^{* * *}$} & {$[0.713]^{* * *}$} & {$[0.708]^{* * *}$} \\
Political rights & -0.466 & -- & -0.064 & -0.382 & -0.047 & -0.681 \\
& {$[0.205]^{* *}$} & -- & {$[0.197]$} & {$[0.336]$} & {$[0.365]$} & {$[0.316]^{* *}$} \\
Constant & 33.597 & -- & 19.807 & 28.803 & 33.582 & 38.57 \\
& {$[4.701]^{* * *}$} & -- & {$[3.544]^{* * *}$} & {$[6.485]^{* * *}$} & {$[5.981]^{* * *}$} & {$[6.077]^{* * *}$} \\
\hline R-squared & 0.26 & -- & 0.26 & 0.21 & 0.26 & 0.34 \\
No. of observations & 2477 & -- & 391 & 566 & 799 & 721 \\
\hline
\end{tabular}

Notes: Standard errors, clustered by country reported in brackets.

Political rights is measured on 1 to 7 scale, where higher values correspond to less political freedom (i.e., more repressive).

Values for political rights are unavailable prior to 1972.

$*$ = significant at $10 \% ; * *=$ significant at $5 \%$ : *** = significant at $1 \%$. 


\section{Appendix G: Foreign aid flows}

Figure G1: Foreign aid (\% GDP) in countries of the "Arab Spring", 1970-2009

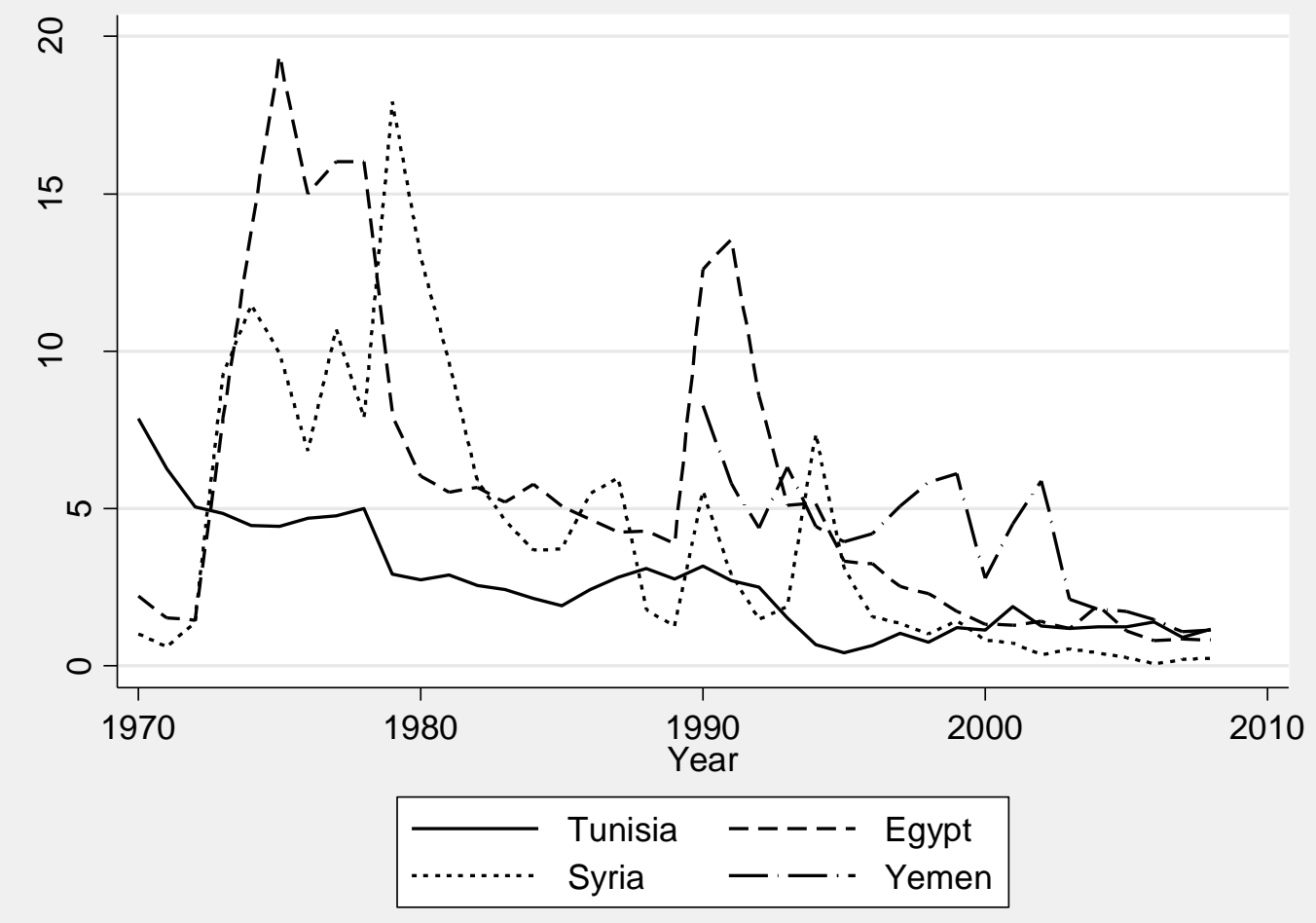

